\title{
Contratos de participación público privada
}

\author{
Public-private participation contracts
}

Contratos de participação público-privada

Contrats de participation public-privé

公私参与合同

\author{
Leandro E. Ferreyra ${ }^{1}$ \\ Universidad de Buenos Aires, Argentina
}

Revista Derechos en Acción ISSN 2525-1678/ e-ISSN 2525-1686

Año 6/No 19 0toño 2021 (21 marzo a 20 junio), 23-83

DOI: https://doi.org/10.24215/25251678e510

Recibido: 01/03/2021

Aprobado: 15/04/2021

Resumen: En este trabajo se realiza una descripción del régimen legal de los contratos de participación público privada (PPP). Asimismo, se presentan las características principales de los contratos PPP. Luego se analiza la programación presupuestaria de los proyectos bajo esa modalidad desde 2018 en adelante. También se abordan los problemas que sufrieron las iniciativas desde aquel año por las turbulencias económicas y financieras que atravesó el país, las que, a su vez, se usaron para justificar un nuevo e irregular préstamo con el Fondo Monetario Internacional (FMI). Las condiciones del FMI conllevaron recortes en el programa de obras, en particular sobre aquellas a consumarse con contratos PPP. De todas maneras, la fragilidad del plan PPP exhibió otras deficiencias de transparencia y sustentabilidad. Por último, se examinan

Abogado, Magíster en Derecho administrativo, profesor de Derecho administrativo, Facultad de Derecho, Universidad de Buenos Aires. Email: leandroferreyra@derecho.uba.ar (ORCID: https://orcid.org/0000-0002-1642-353X).

Agradecimientos: a Raúl Gustavo Ferreyra, Carlos Balbín, Juan González Moras, Delfina Cavallini Viale, José Ignacio López y, especialmente, a José Luis Gioja. 
Ios pocos contratos PPP que se celebraron para corredores viales y se desarrollan las razones de su final.

Palabras clave: Administración Pública - Contratos - Participación público privada - Presupuesto - Fondo Monetario Internacional - Corredores viales - Contratos PPP.

Abstract: In this work is made a description of the legal regime of public-private participation contracts (PPP). Likewise, the main characteristics of PPP contracts are presented. Then, the "budgetary programming" of projects under this modality from 2018 onwards is analyzed. It also addresses the problems that the initiatives suffered since that year due to the economic and financial turbulence that the country went through, which, in turn, were used to justify a new and irregular loan with the International Monetary Fund (IMF). IMF conditions led to cuts in the works program, particularly those to be carried out with PPP contracts. However, the fragility of the PPP plan exhibited other transparency and sustainability deficiencies. Finally, the few PPP contracts that were entered into for highway corridors are examined and the reasons for their termination are developed.

Keywords: Public Administration - Contracts - Public Private Participation - Budget - International Monetary Fund - Road corridors - PPP Contracts.

Resumo: Neste trabalho é feita uma descrição do regime jurídico dos contratos de participação público-privada (PPP). Da mesma forma, são apresentadas as principais características dos contratos PPP. Em seguida, é analisada a programação orçamentária dos projetos nesta modalidade a partir de 2018. Aborda também os problemas que as iniciativas sofreram desde aquele ano devido à turbulência econômica e financeira por que passou o país, que, por sua vez, serviram para justificar um novo e irregular empréstimo com o Fundo Monetário Internacional (FMI). As condições do FMI levaram a cortes no programa de obras, principalmente aquelas a serem realizadas com contratos PPP. No entanto, a fragilidade do plano PPP exibia outras deficiências de transparência e sustentabilidade. Por fim, são examinados os poucos contratos PPP celebrados para corredores rodoviários e elaborados os motivos de sua extinção.

Palavras-chave: Administração Pública - Contratos - Participação Público Privada - Orçamento - Fundo Monetário Internacional - Corredores rodoviários - Contratos PPP. 
Résumé: Dans cet article, une description du régime juridique des contrats de participation public-privé (PPP) est faite. De même, les principales caractéristiques des contrats PPP sont présentées. Ensuite, la programmation budgétaire des projets sous cette modalité à partir de 2018 est analysée. II aborde également les problèmes que les initiatives ont souffert depuis cette année en raison des turbulences économiques et financières que le pays a traversées, qui, à leur tour, ont été utilisées pour justifier un nouveau prêt irrégulier auprès du Fonds monétaire international (FMI). Les conditions du FMI ont conduit à des coupes dans le programme de travaux, notamment ceux à réaliser avec des contrats PPP. Cependant, la fragilité du plan PPP présentait d'autres lacunes en matière de transparence et de durabilité. Enfin, les quelques contrats PPP qui ont été conclus pour les corridors routiers sont examinés et les raisons de leur résiliation sont développées.

Mot-clés: Administration publique - Contrats - Participation publique privée - Budget - Fonds monétaire international - Couloirs routiers - Contrats PPP.

摘要：在这项工作中对公私参与合同的法律制度进行了描述. 同样 介绍了合同的主要特征然后分析了从2018年开始在这种模式下的 项目预算规划. 它还解决了该年以来由于该国经历的经济和金融动 荡而遭受的倡议问题，这些动议又被用来为向国际货币基金组织 -FMI-提供新的不定期贷款辩护. 货币基金组织的条件导致了工作计 划的削减, 特别是与公私伙伴关系合同进行的削减. 但是, 购买力平 价计划的脆弱性还表现出其他透明度和可持续性方面的缺陷. 最后, 检查了为公路走廊签订的几个PPP合同, 并阐明了终止合同的原因.

关键字：公共行政-合同-公共私人参与-预算-国际货币基金组织-公 私参与合同

\section{Introducción}

En el año 2016 fue promulgada la ley 27.328 de contratos de participación público privada (PPP). Este régimen no fue el primero del ordenamiento jurídico argentino sobre la materia, pero sí el primero con esa jerarquía legal. El régimen se gestó 
y promovió con auspiciosos augurios. Hoy en día, los contratos PPP enfrentan dudas terminales.

En esta obra se abordará la historia reciente de los contratos PPP, desde la sanción de la ley hasta la extinción de los pocos que fueron celebrados. El desarrollo intentará respetar el orden cronológico de eventos, sin perjuicio de algunas alteraciones que se introducirán para una mejor comprensión.

\section{Contratos PPP - Antecedentes y preguntas iniciales}

La Administración Pública Nacional cuenta con un régimen general de contrataciones públicas establecido por el decreto -delegado- 1023/2001. Asimismo, la Administración recurre a otros modos de contratación como la ley de obra pública (13.064) y la de concesiones de obras públicas (17.520), también conocida como "de peaje".

Los antiguos números de las leyes de obras públicas y concesiones de obras públicas sugieren que la Administración lleva décadas sin necesitar modulaciones para esos regímenes. La experiencia no es tan contundente. Siempre existieron cuestionamientos y problemas vinculados a estos temas. No solo de índole jurídico, sino también económico y político. La Administración afecta e invierte recursos a través de contratos. Cuando la Administración se demuestra palmariamente deficiente, el instinto nos lleva a preguntarnos cómo dispuso, hizo y gastó para concretar la provisión de bienes y servicios. Y en materia de obras públicas, las erogaciones públicas son mayores y también lo son las irregularidades. Dentro de estas últimas, quedan incluidas las negligencias, los errores, los delitos y la total falta de razonabilidad del diseño institucional de políticas públicas sobre bienes y servicios.

En el año 2016 no resultaba difícil cuestionar el estado corriente de cosas y atacar a los regímenes vigentes. Al momento de pensar y proponer alternativas, alguien dio con los contratos PPP; de dispar suerte en otros países, cuestión que excede este trabajo. Nuestra historia nos enseña -con apabullante 
claridad- que Argentina es única e irrepetible. Quien suponga que un injerto extranjero puede funcionar en este país quizás cometa un exceso de optimismo.

Así llegamos a la ley 27.328 de contratos PPP (ley PPP o ley de contratos PPP).

Anunciada como la panacea para la obra pública y promotora de la transparencia, conquistó al Congreso de la Nación y también se convirtió en ley a nivel provincial ${ }^{2}$. Su presunta esencia: ser diferente a lo anterior. Su supuesto antídoto: repeler a todos los demás regímenes de Derecho administrativo. Su hipotético atractivo: una regulación difusa, que permitiría la concreción flexible de cada proyecto.

Ahora bien, cabe preguntarse: ¿los problemas de la Administración en materia de contrataciones hallaban como causa la deficiente regulación o la irregular aplicación de normas? ¿Que una ley sea especial debe implicar que no se apoye en otros regímenes similares? ¿Es razonable estipular en una ley que la Administración pueda recurrir a un modo de contratación para cualquier cosa cuando otro régimen define esos supuestos? ${ }^{3}$

Más allá de las posibles respuestas a estos interrogantes, hoy existe la ley de contratos de PPP.

\section{La ley 27.328 y su reglamentación - Aspectos generales de los contratos PPP}

¿Qué es un contrato PPP? El artículo 1 de la ley 27.328 establece:

"Los contratos de participación público-privada son aquellos celebrados entre los órganos y entes que integran el sector público nacional con el alcance previsto en el

2 Ley 14.920 de la Provincia de Buenos Aires, ley 3074 de Provincia del Neuquén y ley 8992 de la Provincia de Mendoza, entre otras.

3 Ya sea por objeto (por ejemplo, obras o suministros), o bien por cuantía (ver decreto 1030/2016, artículo 9). 
artículo $8^{\circ}$ de la ley 24.156 y sus modificatorias (en carácter de contratante), y sujetos privados o públicos en los términos que se establece en la presente ley (en carácter de contratistas) con el objeto de desarrollar proyectos en los campos de infraestructura, vivienda, actividades y servicios, inversión productiva, investigación aplicada y/o innovación tecnológica.

Los proyectos que bajo esta ley se desarrollen podrán tener por objeto, una o más actividades de diseño, construcción, ampliación, mejora, mantenimiento, suministro de equipamientos y bienes, explotación u operación y financiamiento. El diseño de los contratos tendrá la flexibilidad necesaria para adaptar su estructura a las exigencias particulares de cada proyecto y a las de su financiamiento, de acuerdo a las mejores prácticas internacionales existentes en la materia.

Los contratos de participación público-privada podrán celebrarse cuando previamente se determine que esta modalidad de contratación permite cumplir con los objetivos de interés público tendientes a satisfacer".

A nivel institucional, en la página oficial de la Subsecretaría de Participación Público Privada se ha publicado la siguiente definición de contratos PPP:

"Los contratos de Participación Público-Privada (PPP) son aquellos celebrados entre los órganos y entes que integran el Sector Público Nacional y sujetos privados o públicos con el objeto de desarrollar una o más actividades de diseño, construcción, ampliación, mejora, mantenimiento, suministro de equipamientos y bienes, explotación u operación y financiamiento.

Este tipo de contratos constituye una modalidad alternativa a los contratos de obra pública y concesión de obra pública, en la que existe una distribución de riesgos entre la autoridad contratante y el contratista, asumiendo este último la responsabilidad por la obtención de una parte sustancial del financiamiento del proyecto" ${ }^{4}$.

4 Sitio web de la Subsecretaría de Participación Pública Privada de la Jefatura de Gabinete de Ministros de la Nación: https://www.argentina.gob.ar/jefatura/ppp/preguntasfrecuentes. 
Quienes celebren contratos PPP serán casi los mismos órganos, entes y organismos que celebran contratos administrativos según el decreto 1023/2001. Incluso el artículo 1 de la ley 27.328 es más amplio, puesto que abarca a todo el Sector Público Nacional previsto por el artículo 8 de la ley 24.156, sin la limitación al inciso a (artículo 2 del decreto 1023/2001) 5 .

En la ley 27.328 se dispone que los contratos tendrán la "flexibilidad necesaria" para cada proyecto en particular. En otras palabras, a través de un contrato PPP la Administración podría celebrar contratos similares a los regulados en otros regímenes, sin restricciones -por ejemplo- en lo que hace al objeto ${ }^{6}$. En un contrato PPP se podrían mezclar objetos y modalidades de otras formas de contratación ${ }^{7}$. La ley exige, no obstante, que se precise que así -con un contrato PPP- se satisfacería el interés público. Lo que debería ser redundante en materia de

5 Susana Vega señala: "Pero además, el contratista PPP no solo puede ser un sujeto privado sino también público: incluso empresas o sociedades en las que el Estado nacional, provincial, municipal o la Ciudad Autónoma de Buenos Aires tengan participación, actuando en igual marco de competencia y condiciones que el sector privado". Ver: VEGA, Susana (2019). “Contrato de obra pública y contrato de participación público privada. Diferentes modalidades para hacer infraestructura" en revista La Ley, 13/6/2019.

6 Artículo 1, Anexo I, Decreto 118/2017 reglamentario de la ley 27.328: “El Ente Contratante podrá incluir en el Contrato PPP cláusulas de cualquier tipo contractual nominado 0 innominado; todo ello en tanto resulte compatible con el régimen de la Ley y adecuado a la naturaleza del Proyecto específico de que se trate. Podrán ejecutarse a través del régimen previsto en la Ley, los Proyectos cuyo objeto sea la provisión de mano de obra, el suministro y provisión de bienes y la construcción o ejecución de obras repagadas con Contraprestación por Uso y/o con Contraprestación Pública".

7 Comenta Gabriela Stortoni que el objeto de un contrato PPP "puede abarcar desde el diseño del proyecto, construcción de obra nueva, ampliación de existente, su mantenimiento, la explotación, operación y el financiamiento (Artículo 1). El régimen, que prima facie incorpora los posibles objetos previstos en la Ley 17.520, va a destacar la "flexibilidad" y con ello la posibilidad de utilizar diversas figuras contractuales y con variados alcances de los compromisos. Podrán ir, entonces, desde una concesión típica por peaje, con recupero de inversión directa del usuario; o el mismo sistema concesional con peaje sombra (esto es presupuesto); o pueden ser desarrollos más novedosos de contrataciones donde el privado desarrolle, construye, explote y luego de un tiempo determinado para el recupero de la inversión, entregue el bien al Estado, o lo explote como dueño con ganancias acotadas para si, o comparte plus de ingresos con el Estado, etc". Ver: STORTONI, Gabriela (2017). "Participación Público Privada en Argentina" en Revista Vial, nº 116. 
funcionamiento estatal ${ }^{8}$. Pero en el artículo 13 inciso a de la ley 27.328 se determina que antes de efectuar la convocatoria a oferentes la autoridad convocante deberá emitir un dictamen en el tendrá que justificar:

“a) La factibilidad y justificación de la contratación mediante la celebración de un contrato de participación público-privada, previa intervención de la unidad de participación público-privada, exponiéndose las razones por las cuáles se considera que el interés público se verá mejor atendido mediante el recurso a esta modalidad frente a otras alternativas contractuales disponibles".

Este punto no es una cuestión menor, puesto que, por un lado, ya se ha indicado que los contratos PPP proponen una alternativa difusa -a concretar en cada caso- a regímenes específicos de contratos de la Administración.

Por otra parte, la ley de contratos PPP excluye expresamente la aplicación de las normas previstas en estos regímenes: ley 13.064, ley 17.520, decreto 1023/2001, el artículo 765 del Código Civil y Comercial $^{9}$ y los artículos 7 y 10 de la ley $23.928^{10}$

8 Lo mismo refieren Héctor A. Mairal y Enrique V. Veramendi: “Al respecto, cabría preguntarse si es correcto 0 , incluso, posible que el Estado actúe fuera "de las funciones públicas que le competen", o que en su actuación no persiga — de alguna manera directa o indirectanecesidades públicas. Si se entiende que el Estado siempre actúa en ese marco, entonces la sola presencia del Estado como parte del contrato determinaría que sus consecuencias se rijan por el derecho público, lo que demuestra el carácter omnicomprensivo de la definición". Ver: MAIRAL, Héctor A. - VERAMENDI, Enrique V. (2018). "Vicisitudes y perspectivas de los contratos del Estado" en revista La Ley 4/12/2018.

9 Artículo 765, Código Civil y Comercial: "La obligación es de dar dinero si el deudor debe cierta cantidad de moneda, determinada o determinable, al momento de constitución de la obligación. Si por el acto por el que se ha constituido la obligación, se estipuló dar moneda que no sea de curso legal en la República, la obligación debe considerarse como de dar cantidades de cosas y el deudor puede liberarse dando el equivalente en moneda de curso legal".

10 Artículo 7, ley 23.928: “. .. En ningún caso se admitirá actualización monetaria, indexación por precios, variación de costos o repotenciación de deudas, cualquiera fuere su causa, haya 0 no mora del deudor, con las salvedades previstas en la presente ley...".

Artículo 10, ley 23.928: "Mantiénense derogadas, con efecto a partir del $1^{\circ}$ de abril de 1991, todas las normas legales o reglamentarias que establecen o autorizan la indexación 
(artículo 31, ley 27.328) ${ }^{11}$. Y hay más exclusiones normativas ${ }^{12}$ en el artículo 9 inciso p de la ley PPP, que consagra que todos los contratos de esta modalidad deberán fijar:

"Las causales de extinción del contrato por cumplimiento del objeto, vencimiento del plazo, mutuo acuerdo, culpa de alguna de las partes, razones de interés público u otras causales con indicación del procedimiento a seguir, las compensaciones procedentes en los casos de extinción anticipada, sus alcances y método de determinación y pago. En el caso de extinción del contrato por razones de interés público, no será de aplicación directa, supletoria ni analógica ninguna norma que establezca una limitación de responsabilidad, en especial las contenidas en las leyes 21.499 y sus modificatorias y 26.944 y en el decreto 1023/2001 y sus modificatorias. La suspensión o nulidad del contrato por razones de ilegitimidad deberá ser solicitada y declarada por el tribunal competente".

\section{Ahora bien, esto no implica que no podrán aplicarse a con- tratos PPP soluciones similares a las previstas para contratos}

por precios, actualización monetaria, variación de costos o cualquier otra forma de repotenciación de las deudas, impuestos, precios o tarifas de los bienes, obras o servicios...".

11 En palabras de Héctor A. Mairal y Enrique V. Veramendi: “Así nació la Ley PPP para poner coto a las extravagancias de la teoría argentina del contrato administrativo, no de una manera general, como hubiera sido de desear, sino limitándolas sólo frente a quienes aceptan invertir en los proyectos comprendidos en esta normativa especial, que ha sido concebida como un régimen alternativo de contratación con el Estado, que excluye la aplicación del Régimen de Contrataciones y de la LRE y reconoce la pertinencia del recurso al derecho privado en forma supletoria y no meramente analógica". También afirman que: "Las prerrogativas comprendidas en la teoría del contrato administrativo no tienen base o fundamento constitucional, por lo que nada impide al legislador excluir su aplicación o limitar su alcance, ya sea en forma general o en relación con cierta clase de contratos". Ver: MAIRAL, Héctor A. - VERAMENDI, Enrique. V., op. cit.

12 Ahora bien, sí existiría una diferencia -en lo que hace a exclusiones- en materia de servicios públicos: “En los casos en que los contratos de participación público-privada involucren la prestación de servicios públicos regidos por marcos regulatorios específicos, dichos marcos regulatorios resultarán de aplicación a la prestación de tales servicios" (artículo 2 , segundo párrafo, ley 27.328). 
administrativos, sino que deberán fijarse expresa y especialmente en cada contrato $^{13}$. $\mathrm{O}$ incluso podrían determinarse -gracias a la "flexibilidad"- otras reglas ${ }^{14}$.

Otro aspecto relevante del régimen de contratos PPP consiste en las soluciones de controversias, ya que se prevén las alternativas de (1) paneles técnicos, (2) arbitraje y (3) prórroga de jurisdicción ${ }^{15}$. De hecho, a través del decreto 1039/2018 se aprobó la prórroga de jurisdicción para los contratos PPP incluidos en el Proyecto "Red de Autopistas y Rutas Seguras PPP - Etapa 1"16, sobre los que se volverá más abajo.

Y cabe subrayar otra nota distintiva de los contratos PPP: el riesgo y/u obligación de obtención de financiamiento a cargo

13 Juan Carlos Cassagne explica que para los contratos PPP “... se prescribe que todas las prerrogativas deben contemplarse en los pliegos y documentación contractual, lo que excluye la posibilidad de que la Administración utilice las llamadas prerrogativas implícitas o sobreentendidas, que, al no encontrar su andamiaje en el ordenamiento positivo, transgreden el principio de legalidad" Ver: CASSAGNE, Juan Carlos (2018). "Las prerrogativas de la Administración en los contratos administrativos. Tendencias actuales sobre el "ius variandi" en revista La Ley, 23/4/2018. Y Ariel Cardaci Méndez indica que: "Con relación a los contratos de Participación Público-Privada (PPP) dichas facultades han sido morigeradas y como bien señala Perrino, ello, con la finalidad de dar previsibilidad y minimizar los conflictos entre las partes y solo podrán ser ejercidas cuando hayan sido expresamente establecidas en la norma y en la medida que estén expresamente contempladas en el respectivo contrato, eliminando de esa manera el "riesgo" de las prerrogativas implícitas antes aludidas". Ver: CARDARCI MÉNDEZ, Ariel (2018). "Las prerrogativas estatales en los contratos administrativos, con especial referencia al contrato de Participación Público Privada" en Revista de Derecho Administrativo, n 119.

14 Además, Juan González Moras indica que la ley de contratos PPP “... sí crea o establece un nuevo derecho real administrativo en el caso de los inmuebles del dominio público, ya que, en este supuesto, la Ley $N^{0} 27.328$ viene a modular o excepcionar, aunque sea en parte, el régimen del art. 237 del Cód. Civ. y Com. en lo que hace a los caracteres del dominio público. De esta forma, este régimen especial crea, dentro de su ámbito de aplicación y para los inmuebles del dominio público del Estado que se afecten a los contratos de participación público-privada, un derecho real administrativo de superficie". Ver: GONZÁLEZ MORAS, Juan M., "Derecho de las cosas y bienes públicos. Dominio público y privado del Estado. Recursos naturales. Bienes colectivos", inédito.

15 Artículos 9, incisos w y x, 25, ley 27.328. La prórroga de jurisdicción para arbitraje solo podrá ser dispuesta por el Poder Ejecutivo y deberá ser informada al Congreso de la Nación.

16 Artículo 3, decreto 1039/2018. 
del contratista ${ }^{17}$. Pese a que la ley 27.328 no lo consigna como regla general ${ }^{18}$, la carga de financiamiento de proyectos PPP recaerá sobre los contratistas y no sobre la autoridad contratante. Esto parece una contradicción regulatoria: lo relevante no se explicita. La cuestión merece esclarecerse, ya que por esto los contratos PPP nunca pudieron emerger. Y aquellos que se adjudicaron, no se pudieron ejecutar porque los contratistas no obtuvieron el financiamiento.

La ley 27.328 regula -con timidez- cuál de las partes del contrato debe conseguir el financiamiento en el artículo 9 inciso n al fijar que toda contratación PPP debe prever "la facultad de la contratante de prestar su cooperación para la obtención del financiamiento que resulte necesario para la ejecución del proyecto". De lo que se deduce que quien contrata no financia ni se ocupa del financiamiento del proyecto $^{19}$, sino que a lo sumo ayuda ("coopera") al contratista a obtener el

17 Manuel Alderete asevera que: “El financiamiento privado es el corazón del contrato PPP, por lo que su estructuración exigió en los hechos una ingeniería jurídica y financiera extraordinariamente compleja". Ver: ALDERETE, Manuel (2019). "Modificaciones al contrato de participación público-privada. El caso de la Red de Autopistas y Rutas Seguras (RARS)" en revista La Ley, 28/10/2019.

18 Susana Vega opina que: “Dado que el factor clave de distinción reposa en la diferente modalidad de financiación y estructura del negocio, las restantes diferencias se generan en muchos casos como consecuencia de esta diferenciación central, sin perjuicio de lo cual, en lo que hace a ciertos aspectos del régimen PPP, surge la reflexión sobre la conveniencia de eventualmente extender la regulación de algunos de estos aspectos al régimen de la obra pública en posibles normativas futuras a dictarse, más allá de las eventuales adaptaciones que pueda resultar necesario efectuar, en función de la distinta modalidad contractual". Ver: VEGA, Susana, op.cit. Juan González Moras enseña que la razón de ser de los contratos PPP está vinculado al sistema de financiación de la ejecución de obras y desarrollo de los contratos por medios y sistemas diversos a los que tradicionalmente contemplan las normas de contratación administrativa. Ver: GONZÁLEZ MORAS, J. M., op.cit.

19 Una deducción parecida se podría extraer del artículo 10 de la ley 27.328: “En todos los casos de extinción anticipada del contrato por parte de la contratante, con carácter previo a la toma de posesión de los activos, se deberá abonar al contratista el monto total de la compensación que pudiese corresponder según la metodología de valuación y procedimiento de determinación que al respecto se establezcan en la reglamentación y en la pertinente documentación contractual, la que en ningún caso podrá ser inferior a la inversión no amortizada. Asimismo, en todos los casos se deberá asegurar el repago del financiamiento aplicado 
financiamiento ${ }^{20}$. Parece un juego de palabras, pero no lo es. Y esta es la principal razón del origen y fin de los contratos PPP.

Además, el decreto reglamentario de la ley PPP determina que:

"Podrán ejecutarse a través del régimen previsto en la Ley, los Proyectos cuyo objeto sea la provisión de mano de obra, el suministro y provisión de bienes y la construcción o ejecución de obras repagadas con Contraprestación por Uso y/o con Contraprestación Pública. Cuando el repago provenga de fondos del Tesoro Nacional, incluyendo recursos provenientes de fideicomisos con afectación específica, debe mediar financiamiento del Contratista PPP, de Entidades Financiadoras y/o de terceros, respecto de los pagos que deban realizarse bajo los Proyectos"21.

Allí se establece que si la Administración pagase una contraprestación en el marco de un contrato PPP, el financiamiento de lo realizado debería provenir de una fuente diferente al Tesoro Nacional o un fideicomiso público ${ }^{22}$. "Fuente de financiamiento" no coincidiría con "fuente de pago" en contratos PPP. O sea que la Administración no financiaría el contrato PPP en esos casos; es decir todos, salvo contrataciones con créditos externos, a los que casi seguro no se les aplicará esta ley $^{23}$.

al desarrollo del proyecto. Lo anterior no implica que el contratista no deba compensar los daños y perjuicios en beneficio del contratante que se hubieran previsto en el contrato".

20 Gabriela Stortoni, por su parte, expresa: "Esta modalidad se incorpora para establecer un reparto de riesgos más equitativo que las modalidades de obra pública o concesión, estricto sensu establecen. Por ende, es clave que cada parte asuma el riesgo que mejor puede cubrir. En esto el sector privado es clave, ya que se trata de que asuma más riesgos que los que normalmente contrae en los contratos públicos. Que termine la obra y luego la cobre en cánones periódicos, donde amortice la inversión, con una cuota referida a mantenimiento, sería una quimera". Ver: STORTONI, Gabriela, op. cit.

21 Artículo 1, Anexo 1, decreto 118/2017.

22 Acerca de fideicomisos públicos consultar: BELLO KNOLL, Susy I. - CASTRO VIDELA, Santiago M. (2020). "El fideicomiso público. La necesidad de control específico para que sea una herramienta útil y transparente, Lejister" en Revista de Contrataciones Públicas, $\mathrm{n}^{0} 4$, diciembre 2020, IJ-MIII-877.

23 Como tampoco el decreto 1023/2001, según el artículo 5 de ese régimen. 
En el decreto reglamentario 118/2017 también se define "Entidad financiadora" como "cualquier persona que otorgue financiamiento al Contratista PPP o en relación con el Proyecto".

Y en el artículo 9 inciso 9 del decreto 118/2017 se estipula:

"A los fines de estructurar el financiamiento del Proyecto, el Contratista PPP podrá contratar préstamos, emitir títulos de deuda con o sin oferta pública, constituir fideicomisos, financieros o no, que emitan títulos de deuda o certificados de participación, crear fondos comunes de inversión y/o cualquier otra estructura financiera susceptible de ser garantizada a través de la cesión de los Contratos PPP y/o de los derechos de crédito emergentes del Contrato PPP ... así como sus correspondientes garantías...".

Asimismo, si la Administración pudiese financiar de forma directa un proyecto, recurriría a las alternativas típicas, como alguna de las excluidas para PPP, como la ley 13.064 o el decreto 1023/2001. O, tal vez, si no tuviese medios inmediatos para el financiamiento, a la concesión de obra pública. Por cierto, el artículo 7 de la ley 17.520 prevé un supuesto de financiación a cargo del contratista ${ }^{24}$. Así, ni siquiera esta nota sobre el financiamiento sería propia de los contratos PPP. En todo caso, solo justificaría a los contratos PPP la reunión de todos los caracteres enunciados, a saber:

- flexibilidad, cuyo grado dependerá de lo que se precise en cada contrato;

- exclusión de normas típicas de Derecho administrativo ${ }^{25}$;

- financiamiento a cargo del contratista.

\footnotetext{
24 Artículo 7, ley 17.520: "En los casos en que las inversiones motivo de la concesión fuesen a ser financiadas con recursos del crédito a obtenerse por el Estado o por el concesionario con la garantía de éste, la concesión -además de prever los procedimientos de fijación y ajuste de tarifas- deberá contener las disposiciones que aseguren la amortización y servicio de las deudas y obligaciones a contraerse, así como la obligación del Estado de proveer el eventual defecto de ingresos si las tarifas autorizadas o reajustadas no resultasen suficientes".

25 ¿Los contratos PPP serían contratos de la Administración pero no de Derecho administrativo? ¿Un contrato PPP estaría regido por Derecho público? Sobre las categorías referidas
} 


\section{La ley de presupuesto para el ejercicio 2018 - Proyectos, el fideicomiso PPP y la deuda pública}

La ley 27.328 fue sancionada en noviembre de 2016 y reglamentada en febrero de 2017. Por ende, no había previsión administrativa ni presupuestaria sobre contratos PPP para el ejercicio 2017. Pero llegaba el año 2018 y se enfrentó una necesidad: proyectar obras a través de contratos PPP.

Sin embargo, y como todos los años, a fines de 2017 se aprovechó la ocasión para agregar artículos en el proyecto de ley de presupuesto sobre otros temas. Por ejemplo, contratos PPP. Así fue que la ley de presupuesto 2018 (27.431) contó con un capítulo regulatorio y con algunas planillas (A y B, anexas a la ley) sobre estos contratos.

En cuanto a la nueva regulación introducida por esa ley, primero se creó el Fideicomiso $\mathrm{PPP}^{26}$ y se fijó la posibilidad de crear fideicomisos individuales PPP, los que "se conformarán como fideicomisos de administración, financieros, de pago y de garantía”. Además, se estipuló la exención para los fideicomisos PPP "de todos los impuestos, tasas y contribuciones nacionales existentes y a crearse en el futuro, incluyendo el Impuesto al Valor Agregado y el Impuesto sobre los Créditos y Débitos en Cuentas Bancarias y Otras Operatorias".

Asimismo, se incluyó esta regla en el artículo 60 de dicha ley:

"Las obligaciones y compromisos que asuman el Fideicomiso PPP y/o los Fideicomisos Individuales PPP y el Estado nacional con el Fideicomiso PPP y/o los Fideicomisos Individuales PPP, en relación con contratos o proyectos de participación público-privada celebrados o ejecutados de conformidad con los términos de la ley 27.328 , no serán

-Derecho administrativo y Derecho público- se puede consultar: FERREYRA, Leandro E. (2017). La regulación de la responsabilidad del Estado. Ediar, Buenos Aires.

26 Reglamentado por el decreto 153/2018. 
considerados deuda pública en los términos del título III de la ley 24.156 y sus modificaciones" ${ }^{27}$.

A su vez, el artículo 61 de la ley de presupuesto 2018 listó como beneficiario del fideicomiso de impuesto sobre el gasoil (decreto 976/2001) justamente a los fideicomisos PPP "para obras de infraestructura de transporte vial y ferroviaria en todo el territorio nacional". Los artículos 64 y 67 hicieron algo similar con los fideicomisos del Programa Crédito Argentino del Bicentenario para la Vivienda Única Familiar (decreto 902/2012) y de tasa de infraestructura hídrica (decreto 1381/2001) y proyectos vinculados a esas áreas.

Y se sumarían más buenas noticias para los contratos PPP en esa misma ley de presupuesto 2018: se determinó en el artículo 74 que a las operaciones, certificados, valores negociables y títulos valores fiduciarios PPP no se les aplicaría la Ley de Impuesto a las Ganancias.

Así, parecía que se alcanzaba la sustentabilidad de la propuesta. Habría recursos, las operaciones estarían separadas del Derecho administrativo y desgravadas y las emisiones no serían deuda pública. O eso se pretendió comunicar.

Sin embargo, ese presupuesto 2018 también incluyó planillas de "obras o adquisición de bienes y servicios" (anexa al artículo 11) y de "obras PPP" (anexa al artículo 59) ${ }^{28}$. Las primeras contenían gastos equivalentes a -aproximadamente31 mil millones de pesos para el ejercicio 2018 y 85 mil millones de pesos para 2019. Por su parte, las planillas de obras PPP suponían erogaciones por cero pesos para 2018 y 2019. Ello se debe a que los títulos por los que se pagarían las obras PPP $^{29}$ recién se cancelarían a los dos años.

\footnotetext{
27 El destacado me pertenece.
}

28 Sitio web del Ministerio de Economía de la Nación: https://www.economia.gob.ar/onp/ presupuestos/2018.

29 La ejecución y avance de las obras se irían certificando, en el caso de los contratos PPP viales, por ejemplo, a través de "Títulos de Pago por Inversión" (TPI), emitidos en dólares. 
Si se continuase con la comparación de esas planillas para ejercicios subsiguientes y el "resto", se advertiría que la cuestión cambiaría. Para 2020 se preveían gastos de obras, bienes y servicios "tradicionales" por 132 mil millones de pesos y para el "resto" de ejercicios por 238 mil millones. El total previsto para gastos de obras, bienes y servicios de la planilla anexa al artículo 11 de la ley de presupuesto era de alrededor de 486 mil millones de pesos. Las erogaciones planificadas para proyectos bajo modalidad PPP fueron de 43 mil millones de pesos respecto al ejercicio 2020 y de 2 billones de pesos para el "resto" de ejercicios ${ }^{30}$. Suma que, por cierto, se desagrega en esas planillas para los ejercicios 2021 a 2034 y que se aplicaría a 102 proyectos diferentes ${ }^{31}$.

En otras palabras, la previsión presupuestaria para obras a ejecutar con contratos PPP en 2018 era cinco veces más grande que para obras y adquisiciones "tradicionales" y se comprometerían recursos públicos por lo que en ese momento eran 114 mil millones de dólares ${ }^{32}$.

Es entonces un buen momento para recordar dos disposiciones de la ley de contratos PPP:

- artículo 4, inciso h: "En la oportunidad de estructurarse proyectos de participación público-privada y teniendo en consideración las circunstancias y características de cada

\footnotetext{
$30 \$ 2.140 .997 .795 .068$, el número exacto. A su vez, es pertinente señalar que la previsión presupuestaria no implica un compromiso de recursos públicos, lo que recién acaecería ante la licitación, adjudicación y ejecución de cada proyecto.

31 Por otro lado, esas planillas de obras por modalidad PPP sirvieron -como suele sucederpara cautivar el apoyo de gobernadores y legisladores que no son del mismo color político. Una vez caídas esas obras, también desapareció el afecto prestado.

32 Es decir que las proyecciones presupuestarias de contratos PPP equivalían a alrededor del 20\% del PBI de Argentina 2017. Según los cálculos de Ricardo Carciofi, al 17\%. Por cierto, Carciofi apuntó sobre los proyectos PPP del presupuesto 2018 que serían “... iniciados en el próximo bienio y cuya ejecución se completaría mayormente en un plazo de cinco años". Ver: CARCIOFI, Ricardo (2018), "El Memorándum con el FMl y el ajuste de la inversión pública", En Alquimias Económicas, 11/7/2018, disponible en: https://alquimiaseconomicas. com/2018/07/11/el-memorandum-con-el-fmi-y-el-ajuste-de-la-inversion-publica/\#_ftn5.
} 
proyecto, la contratante deberá: ... Incentivar la aplicación de mecanismos de solidaridad intrageneracional, intergeneracional e interregional, en la financiación de los proyecto". - Artículo 6: "Las erogaciones y compromisos que se asuman en el marco de proyectos de participación público-privada deberán ser consistentes con la programación financiera del Estado, en un marco de responsabilidad fiscal y de la debida rendición de cuentas, en los términos de las leyes 24.156, 25.152 y demás legislación vigente.

El Poder Ejecutivo nacional deberá informar al Honorable Congreso de la Nación el impacto fiscal de los compromisos asumidos y deberá incorporar dichos impactos fiscales en las respectivas leyes de presupuesto, tanto en lo referente a los proyectos iniciados y no concluidos como los adjudicados pero no comenzados".

¡Cuánta solidaridad intergeneracional mostraba el presupuesto 2018 en materia de obras a realizarse por contratos PPP! Casi tanta como la que se consumó pocos meses después al comprometer al país con el Fondo Monetario Internacional (FMI) por un empréstito de más de 50 mil millones de dólares sin aprobación del Congreso de la Nación.

¡Cuánta responsabilidad fiscal tenían esas proyecciones presupuestarias por miles de millones de dólares! Casi tanta como la que invocó a los pocos meses el Poder Ejecutivo de la Nación para defender el préstamo contraído con el FMI.

Se llega, además, a la paradoja PPP: el Estado contrataría a través de esta modalidad por billones de pesos -o miles de millones de dólares- sin que eso sea deuda pública "en los términos de la ley 24.156" (artículo 60 de la ley 27.431, citado más arriba), pese a que las contraprestaciones se pagarían a través de títulos ${ }^{33}$. De hecho, no se contabilizarían como gastos hasta 2020, ya que recién ese año operarían las primeras

33 Encima de títulos denominados en moneda extranjera para los pocos contratos PPP que se llegaron a celebrar. 
cancelaciones de aquellos títulos. Y la paradoja tendría un complemento: las obras involucradas en esos contratos las ejecutarían contratistas con un financiamiento particular que -al fin y al cabo- dependería del estado económico-financiero de la Nación; medido, por ejemplo, a través del índice "riesgo país".

Así las cosas, los contratos PPP se pagarían con títulos que no serían deuda pública (pero sí, eventualmente, gasto público por billones de pesos o miles de millones de dólares) y el financiamiento privado respondería a la salud que el mercado de capitales estimare para la emisión de deuda pública.

\section{Turbulencias del año 2018: los contratos PPP en jaque}

En 2018 pasaron muchas cosas en Argentina. Se había regresado al mercado internacional de crédito después de varios años, pero, de repente, el esquema se resquebrajó. Sequía, errores macroeconómicos, demasiada emisión de deuda, un contexto internacional adverso, una sobrerreacción de los socios financieros, entre otros, son algunos de los componentes de la bomba que destruyó el estado económico-financiero de Argentina en 2018. O bien "turbulencias", como las denominó el entonces Presidente Mauricio Macri. Cualquiera sea la razón, lo cierto es que el modelo económico adoptado por aquella conducción política quedó muy condicionado, o acaso aniquilado.

Las previsiones presupuestarias para 2018 y los ejercicios subsiguientes también acusaron el golpe. En rigor, las previsiones habían sido fulminadas en una conferencia de prensa del 28 de diciembre de 2017 por integrantes del Gabinete. Pero en Argentina ya no sorprende que una ley de presupuesto sea desarmada por el propio el Gobierno a pocos días de su sanción.

Para resistir a las turbulencias Argentina solicitó en 2018 un salvataje financiero al FMI. El crédito se otorgó según la modalidad "stand-by" y ascendió a 57.100 millones de 
dólares $^{34}$. En junio el FMI aprobó un acuerdo a favor de Argentina por 50 mil millones y en septiembre ${ }^{35}$ tuvo que aprobar una ampliación por el resto para que su deudor no colapsare al corto plazo.

El Poder Ejecutivo, apoyado en el artículo 60 de la ley de Administración financiera (24.156), celebró un acuerdo con el FMI sin intervención del Congreso de la Nación. Dicho artículo prescribe en sus partes pertinentes que:

"Las entidades de la administración nacional no podrán formalizar ninguna operación de crédito público que no esté contemplada en la ley de presupuesto general del año respectivo o en una ley específica...Se exceptúa del cumplimiento de las disposiciones establecidas precedentemente en este artículo, a las operaciones de crédito público que formalice el Poder Ejecutivo Nacional con los organismos financieros internacionales de los que la Nación forma parte"36.

Sin embargo, la ley 24.156 es previa a la reforma constitucional de 1994. En la disposición transitoria octava del texto constitucional aprobado en aquel año se estableció que las legislación delegada quedaría sujeta a un plazo de caducidad de cinco años ${ }^{37}$. Dicho plazo se extendió sucesivamente pero

34 Información oficial provista por el FMl sobre el primer acuerdo en junio de 2018: https:// www.imf.org/es/News/Articles/2018/06/20/pr18245-argentina-imf-executive-board-approves-us50-billion-stand-by-arrangement.

35 Información oficial provista por el FMl sobre el segundo acuerdo en septiembre de 2018: https://www.imf.org/es/News/Articles/2018/09/26/pr18362-argentina-imf-and-argentina-authorities-reach-staff-level-agreement.

36 Esta disposición legal es una excepción a las atribuciones constitucionales del Congreso de la Nación previstas en el artículo 75 inciso 4, 7 y 8: "4. Contraer empréstitos sobre el crédito de la Nación. 7. Arreglar el pago de la deuda interior y exterior de la Nación. 8. Fijar anualmente, conforme a las pautas establecidas en el tercer párrafo del inc. 2 de este artículo, el presupuesto general de gastos y cálculo de recursos de la administración nacional, en base al programa general de gobierno y al plan de inversiones públicas y aprobar o desechar la cuenta de inversión".

37 Disposición transitoria octava de la Constitución Nacional, texto de 1994: “La legislación delegada preexistente que no contenga plazo establecido para su ejercicio caducará a los 
la caducidad operó en agosto $2010^{38}$. Por lo que la delegación prevista por el artículo 60 de la ley 24.156 no se podría aplicar. Ni se debía aplicar en 2018.

Asimismo, la operación de crédito con el FMI contó con más irregularidades. En el caso "Codianni" 39 , la Cámara de Apelaciones en lo Contencioso Administrativo Federal ordenó al Estado Nacional que provea la información pública que le fue solicitada en lo concerniente a los antecedentes y demás documentación sobre la operación crediticia ${ }^{40}$. A partir del material que se pudo obtener y del que no existe, se determinó, entre otros puntos, que:

- el primer expediente sobre el préstamo fue creado en el Ministerio de Hacienda nueve días después de la firma de la primera Carta de Intención para solicitar el crédito (del $12 / 6 / 2018)$.

- No hay constancia de dictamen jurídico previo para firma de dicha Carta.

- No hay constancia del dictamen previo del Banco Central de la República Argentina sobre el impacto del crédito, lo que es exigido por el artículo 61 de la ley $24.156^{41}$.

cinco años de la vigencia de esta disposición excepto aquella que el Congreso de la Nación ratifique expresamente por una nueva ley".

38 Ante el inminente vencimiento de dicho plazo de cinco años, en 1999 se dictó la ley 25.148 que ratificó de forma genérica todas las delegaciones previas a 1994 y las prorrogó por tres años. Mismo objeto, aunque distintos plazos, tuvieron las leyes 25.645 (2002), 25.918 (2004), 26135 (2006) y 26.519 (2009). Esta última ley dispuso un plazo más de vigencia de un año desde el 24 de agosto de 2009 (artículo 1) que nunca más fue renovado por otra ley. Para más detalle sobre vigencia de las delegaciones previas a 1994 ver: FERREYRA, Leandro $E$ (2017), "Las retenciones y el principio de legalidad en materia tributaria" en DPI, Diario Tributario, Aduanero y Financiero $n^{0} 179$, fecha 1/11/2017, disponible en: https://dpicuantico.com/ sitio/wp-content/uploads/2017/10/Ferreyra-Tributario-1.11.pdf.

39 “Codianni, Eduardo Julio c/ EN s/Amparo Ley 16.986", expediente n 7651/2019, Cámara Nacional de Apelaciones en lo Contencioso Administrativo Federal.

40 Para más información consultar https://fmiargentina.com/caso-codianni.

41 Artículo 61, ley 24.156: “En los casos que las operaciones de crédito público originen la constitución de deuda pública externa antes de formalizarse el acto respectivo y cualquiera sea el ente del sector público emisor o contratante, deberá emitir opinión el Banco Central de la República Argentina sobre el impacto de la operación en la balanza de pagos". 
- No se habría suscripto acuerdo alguno, sino solo emitido esa Carta de Intención.

- No hubo acto administrativo ni informe técnico previo a aquella Carta ${ }^{42}$.

Más allá de esos vicios, el crédito del FMI afectó a los proyectos PPP. En la primera Carta de Intención y en otra documentación oficial se asentó que Argentina debería hacer un "esfuerzo fiscal" ${ }^{43}$, que era un eufemismo para reducción de gastos por casi un 1,5\% del PBI para 2018 y de 3,7\% hasta 2020 inclusive. Aquella carta llevaba un documento anexo denominado "Memorándum de políticas económicas y financieras" ${ }^{4}$. Allí se expresaba que:

- "estamos comprometidos a llevar adelante un manejo proactivo de la deuda para extender los vencimientos de los títulos, optimizar el costo de nuestros pasivos y aumentar el porcentaje de la deuda pública nacional denominada en pesos".

- "Reduciremos el gasto en compras de otros bienes y la adquisición de servicios por parte del gobierno nacional un $15 \%$ en términos reales durante 2018 en relación con el gasto de 2017 y continuaremos con dicho proceso en 2019".

- "Continuaremos con la ejecución de los proyectos de obra pública esenciales para promover la competitividad del país, pospondremos aquellos que no lo sean".

En 2018 se estimó que el programa fiscal acordado con el FMI supondría un recorte del $80 \%$ de la inversión pública total para el año $2020^{45}$.

\footnotetext{
42 Ver: https://fmiargentina.com/introduccion.

43 "Acuerdo Argentina-FMI", presentación del Ministerio de Hacienda y Presidencia de la Nación de junio de 2018, disponible en https://www.argentina.gob.ar/sites/default/files/ acuerdo_argentina-fmi-final1.pdf.

44 Disponible en: 1)https://www.argentina.gob.ar/economia/finanzas/deudapublica/cartade intencionmemorandumdepoliticaseconomicas; 2) https://fmiargentinahome.files.wordpress. com/2019/05/2018-06-12-carta-y-memos-1er-crc3a9dito.pdf.

45 “En síntesis, el programa fiscal acordado con el FMI supone un recorte de la inversión pública del gobierno nacional de $50 \%$ por año en términos reales durante el trienio del stand by.
} 
Asimismo, en aquella Carta de Intención de junio de 2018 se incluyó un apartado titulado "Memorándum de entendimiento técnico”. Allí apareció una pauta sobre cómo deberían considerarse a las emisiones y gastos vinculados a proyectos PPP:

"Las asociaciones de participación público-privada (PPP) financiadas por el Gobierno serán tratadas como adquisiciones públicas tradicionales. Las obligaciones del Gobierno nacional asociadas con las participaciones público-privadas se registrarán de forma transparente en las cuentas fiscales y se medirán como parte del déficit del Gobierno nacional a medida que se produzcan (método en base caja)".

El préstamo con el FMI se contrajo pese a la Constitución y a la ley. Pero por el FMI los compromisos asumidos por el Estado Nacional a través de contratos PPP deberían registrarse de forma un poco más "transparente" en cuentas fiscales. Así, era difícil confiar en el cumplimiento de esa pauta.

De hecho, ese Memorándum lo redactó el propio Gobierno ${ }^{46}$ que sostenía esos contratos, por eso no regaló más detalles sobre cómo se consumaría la transparencia. Por cierto, la Jefatura de Gabinete de Ministros de la Nación -en su informe n ${ }^{\circ} 118$ enviado al Congreso de la Nación en $2019^{47}$ - afirmó que las obligaciones vinculadas a los contratos PPP, primero, seguirían sin considerarse deuda pública y que ello no supondría contradicción alguna con lo consignado en el Memorándum. Segundo,

En el caso de 2018, se presenta la dificultad adicional de instrumentar el ajuste en los seis meses de la segunda mitad del año. Es más, si se compara el comienzo con el fin del programa, la inversión prevista para 2018 de 2,5 \% del PBI, incluyendo PIP y PPP, se reduciría en 2020 a 0,3 \% del PBI -es decir, 12\% del nivel inicial. Este valor es un mínimo histórico y levanta la pregunta cómo habrá de mantenerse un mínimo nivel de calidad de los servicios de infraestructura. Esta meta del MPEF parece alejada de planteo oficial de la inversión como una prioridad del Estado Nacional postulado en el Presupuesto del corriente año". Ver: CARCIOFI, Ricardo, op.cit.

46 No se puede imputar al Poder Ejecutivo por completo la Carta de Intención, pues llevó la firma solamente del Ministro de Economía, Nicolás Dujovne, y del Presidente del Banco Central, Federico Sturzenegger.

47 Disponible aquí: https://www.argentina.gob.ar/jefatura/informes-al-congreso. Para información sobre "Inversiones de PPP" ver páginas 256 y subsiguientes. 
que el "repago" de la inversión de proyectos PPP ya adjudicados estaba programado a partir de 2020, por lo que "no está previsto para el ejercicio 2019 afectar recursos del Estado Nacional”.

A pesar de ello, estaba claro que no existía semejante armonía en lo concerniente a los recursos públicos en el marco de contratos PPP y que las emisiones de títulos de pago siempre fueron y debieron ser considerados deuda pública -ya sea directa o indirecta- en los términos de la ley $24.156^{48}$.

Volviendo a 2018, en aquel año se provocó una tormenta para los contratos PPP por dos razones: 1) el aumento del riesgo país, que pasó de 350 puntos a 850 entre enero y diciembre de 2018; y 2) la causa judicial de "las fotocopias de los cuadernos", o de "los cuadernos", en la que quedaron involucrados por delitos de corrupción personas eran dueñas, representantes o socias de varias de las empresas a las que se les adjudicaron los contratos PPP viales.

¿Por qué el aumento del riesgo país fue crítico para los contratos PPP? Porque los contratos entonces previstos (los PPP viales y los próximos) dependerían del "cierre financiero" que aportase cada contratista. Repasemos la gracia de los PPP: supondrían gasto (por emisión de títulos) que no sería deuda,

48 Por su parte, la Oficina de Presupuesto del Congreso (OPC) ha indicado que: "El marco normativo vigente determina que los Títulos por Inversión (TPI) que emite el Fideicomiso PPP RARS como contraprestación de la construcción realizada por los contratistas no son legalmente considerados como deuda pública. No obstante, hay determinadas características de Ios TPI que los asemejan conceptualmente a un bono soberano. Los TPI constituyen un pasivo irrevocable del Fideicomiso PPP, que es un ente del Sector Público no Financiero (SPNF). Su repago, que no está condicionado a la finalización o desempeño del proyecto, se realizará principalmente con fondos originados en tributos nacionales (impuesto a los combustibles) y, en caso de que estos no llegaran a ser suficientes, será en última instancia cubierto con aportes del Tesoro. Es decir que su amortización constituye una necesidad financiera para el SPNF...Por otra parte, aunque no sean legalmente considerados como deuda pública, las mejores prácticas internacionales recomiendan que los compromisos fiscales derivados de los proyectos PPP sean reportados y analizados junto con las estadísticas de deuda pública, de manera de incrementar la transparencia en relación a los pasivos del sector público". Ver: Informe sobre "Impacto fiscal de los proyectos de participación público privada", OPC, 2018, p. 29-30, disponible en https://www.opc.gob.ar/categoria/otras-publicaciones. Asimismo, ver artículos 56, 57 y 58 de la ley 24.156. 
aquel sería paulatino y a concretarse a varios años, siempre y cuando el contratista ejecutare efectivamente las obras previstas. Si los contratistas no obtuvieran el financiamiento, no podrían cumplir con el "cierre financiero", no habría inversiones y mucho menos obras ejecutadas.

En junio de 2018, mismo mes en el que el FMI prestaba 50 mil millones de dólares, la Dirección Nacional de Vialidad (DNV) dictó la resolución $1126^{49}$ por la que dispuso la adjudicación de seis corredores viales bajo modalidad PPP. La causa de "las fotocopias de los cuadernos" se viralizó en agosto de ese año. Todo aquello, sumado a la frágil situación económica-financiera del Estado Nacional y del país, hizo que arreciara la tempestad sobre los contratos PPP adjudicados.

Dado que el financiamiento privado parecía imposible, se comenzaron a analizar alternativas para que continuasen de alguna forma. Por ejemplo, se consideró que el Estado Nacional crease un fideicomiso para financiar -no para pagar, para eso ya existían otros fideicomisos- a los contratistas, pese a que así se desnaturalizaba por completo a la modalidad PPP. Además, se barajó que el fideicomiso estuviese compuesto por los fondos integrados por los adjudicatarios como garantías, o bien por recursos aportados por el Banco Nación. Esto fue publicado, entre otros medios, por el diario La Nación ${ }^{50}$, en el que semanas antes se destapaba como primicia el asunto de "los cuadernos". En paralelo, esto causaba escozor entre los propios periodistas de aquel medio, como Hugo Alconada Mon, quien resumió la cuestión de manera elocuente: "De los PPP a los PPPPP (Plata Pública Protege a Privados Prebendarios)" ${ }^{51}$.

\footnotetext{
49 Resolución 1126/2018, 18/7/2018, disponible en https://www.boletinoficial.gob.ar/ detalleAviso/primera/185946/20180619.

50 Lanzan medidas para blindar la obra pública en medio del escándalo de los cuadernos, Diario La Nación, 29/8/2018, firmada por Sofía Diamante, disponible en https://www.lanacion. com.ar/economia/ppp-nid2166135.
}

51 29/8/2018. Ver: https://twitter.com/halconada/status/1034778084069789698?s=20. 


\section{Las iniciativas PPP - Todo lo que no fue}

Como se aludió anteriormente, el proyecto de presupuesto para el 2018 contenía previsiones para más de un centenar de obras a realizarse por contratos PPP. En la página de internet de la Subsecretaría de Participación público privada ${ }^{52}$ aún se pueden encontrar los vestigios de esas iniciativas y de otras contenidas en el presupuesto para el ejercicio $2019^{53}$ y en el proyecto de ley para 2020. Salvo los contratos PPP viales, el resto quedó en eso: anuncios, señuelos y promesas.

La Subsecretaría todavía ${ }^{54}$ publica y clasifica las iniciativas PPP en cuatro categorías: 1) Energía y minería; 2) Transporte, comunicación y tecnología; 3) Agua, saneamiento y vivienda; y 4) Educación, salud, justicia y defensa. Las hay -hubo- de todo tipo, aunque se destacan por cantidad las de transporte y viales. Por mi parte, aprovecho para destacar mi favorita: la ampliación de la Base Antártica Petrel por 55 millones de dólares ${ }^{55}$. Además, no aparece en las planillas anexas al presupuesto 2018 ni 2019 sino en el proyecto de ley de presupuesto para el ejercicio 2020 que nunca se aprobó, lo que solo la hace más fascinante.

De todas maneras, en la planilla de obras PPP del presupuesto 2018 también aparecen tres complejos penitenciarios, siete hospitales, siete plantas depuradoras, la Red de Expresos

\footnotetext{
52 Se reitera el vínculo: https://www.argentina.gob.ar/jefatura/evaluacion-presupuestaria/ppp.

53 En el presupuesto para el ejercicio 2019 se preveían más de 80 proyectos por modalidad PPP por más de 70 mil millones de dólares.

Ver: https://www.economia.gob.ar/onp/presupuestos/2019. Aunque según el Ministerio de Hacienda reportarían "US\$38.000 MM de inversión". Ver presentación del Ministro de Transporte Guillermo Dietrich en fecha 9/10/2018 disponible en: https://www.hcdn.gob.ar/ export/hcdn/comisiones/especiales/cbscppp/Presentaciones/PresentacionMinistrodeTrans porteGuillermoDietrich9-10-2018.pdf.
}

54 Al 25/1/2021.

55 Ver: https://www.argentina.gob.ar/jefatura/ppp/energia-y-mineria/educacion-salud-yjusticia. La planilla anexa al proyecto de presupuesto para el ejercicio 2020 que preveía esta iniciativa se puede consultar aquí: https://www.economia.gob.ar/onp/presupuestos/2020. 
Regionales (RER) ${ }^{56}$, un parque eólico, una línea ferroviaria que conectaría Añelo con Bahía Blanca ${ }^{57}$, siete líneas de alta tensión, cinco acueductos, entre otros. A lo que hay que añadir otras obras previstas en el presupuesto 2019 y en el proyecto de presupuesto 2020. Qué lástima ese país faraónico que no fue.

Para cerrar este apartado se comenta que una iniciativa de construcción línea de alta tensión sí avanzó con su trámite ${ }^{58}$. Se trata de la línea que iba a vincular Río Diamante, Provincia de Mendoza, con Charlone, Provincia de Buenos Aires. En marzo de 2019 se llamó a licitación pública, pero en noviembre se postergó la fecha de cierre. Con cambio de gestión de por medio, en marzo de 2020 el Ministerio de Desarrollo Productivo dispuso dejar sin efecto el llamado. Entre las razones que motivaron dicha decisión se hallan: 1) que la obra referida no representaría un ahorro para los usuario, quienes, a fin de cuentas, pagarían el costo del proyecto; 2) que en la actualidad no hay acceso al crédito a tasas razonables; y 3) que se atraviesa en un estado de emergencia económica, financiera y energética declarado por la ley $27.541^{59}$.

\section{El control del Congreso de la Nación}

La ley 27.328 de contratos PPP dispuso en su artículo 30 la creación de la Comisión Bicameral de Seguimiento de Contratos de Participación Público-Privada (en adelante, la Comisión), integrada por siete senadores y siete diputados de la Nación. Tiene como misión efectuar el seguimiento de los proyectos desarrollados bajo contratos PPP y el cumplimiento del régimen.

\footnotetext{
56 Aunque por estos días aparece publicitada como un proyecto de la Ciudad Autónoma de Buenos Aires. Ver: https://www.buenosaires.gob.ar/rer.

57 Añelo, Provincia del Neuquén, un centro operativo del yacimiento Vaca Muerta - Bahía Blanca, Provincia de Buenos Aires, puerto estratégico.

58 Aquí se puede consultar toda la documentación relacionada con este proyecto: https:// www.argentina.gob.ar/jefatura/ppp/energia-y-mineria/documentacion-te-e1.

59 Resolución n 124/2020, Ministerio de Desarrollo Productivo. Disponible aquí: https:// www.argentina.gob.ar/sites/default/files/reso_124_mdp.pdf.
} 
A esos fines, la ley prevé que la Comisión cuente con acceso a la documentación, incluidos los contratos que se suscriban sin que se le puedan oponer cláusulas de confidencialidad.

Esta Comisión formuló dos pedidos de informes a la Subsecretaría PPP en 2018. El primer informe se solicitó en junio de 2018 (pocos días después de la resolución que adjudicó los contratos PPP viales) y el segundo, en noviembre de 2018. Tanto los requerimientos como sus respuestas pueden consultarse en la página oficial de la Comisión ${ }^{60}$.

Del primer informe aportado por la Subsecretaría a la Comisión se pueden destacar varios puntos.

En primer lugar, se afirmaba que los fondos provenientes del fideicomiso al que se afecta la recaudación del impuesto al gasoil (decreto 976/01, referido más arriba) "no sólo alcanzarán para el repago de las obligaciones económicas resultantes del Contrato PPP sino que quedará un "remanente" y que "eventualmente, sólo en la medida en que fuere necesario" se acudiría a "aportes contingentes" presupuestarios ${ }^{61}$.

En segundo lugar, se señalaba que el costo financiero "es afrontado por el Contratista PPP, quien es el que debe decidir cuál es el máximo costo financiero que aceptará".

\footnotetext{
60 Ver: https://www.hcdn.gob.ar/comisiones/especiales/cbscppp/requerimientos_de_informacion.

61 Por cierto, el decreto 301/2018 estableció en su artículo 2 nuevas pautas de distribución de lo recaudado y afectado al Fideicomiso del decreto 976/01. En el artículo 3 se determinó destinar "los fondos con cargo al Sistema Vial Integrado (SISVIAL) al Fideicomiso Individual PPP que se constituya conforme lo previsto en el artículo 60 de la Ley $N^{0} 27.431$ para el Programa Red de Autopistas y Rutas Seguras (RARS) con el objeto de asegurar el cumplimiento de las obligaciones asumidas de conformidad con lo establecido en el artículo 23, inciso g) del Decreto $N^{0}$ 976/01, sus normas modificatorias, concordantes y complementarias. Asimismo, se destinarán, a los fines establecidos en los incisos h) e i) del artículo 23 del Decreto Nº 976/01 y sus modificatorios, los fondos excedentes luego de asegurados los compromisos asumidos y/o pendientes con cargo al Fideicomiso de Participación Público Privada, instrumentado por el Decreto No 153 del 23 de febrero de 2018, y el Contrato de "Fideicomiso Individual PPP Red De Autopistas Y Rutas Seguras", manteniendo en uno coma cero cinco $(1,05)$ veces las obligaciones de pago del mismo, del monto de reserva TPI Requerido, del monto de reserva TPI Variable Requerido y del monto de reserva TPD Requerido, así como de las obligaciones pendientes y liquidaciones finales de los Contratos PPP extintos".
} 
En tercer lugar, respecto a los contratos PPP viales se indicó que se eligió esa modalidad contractual -y no otra- porque permitiría concretar obras al corto plazo pese a "la escasez o insuficiencia de recursos estatales disponibles" y "sin afectar el presupuesto público".

Por otro lado, se consultó a la Subsecretaría PPP si respecto a los contratos viales "se realizó una evaluación de costos, riesgos y beneficios previa para descartar la modalidad de contratación clásica de obra pública”. Y se respondió que, con el fin de evaluar si la modalidad PPP resultaría o no más conveniente que la de "obra pública tradicional"62, se utilizó una metodología de análisis de "Valor por dinero'" (VpD). Dicho examen arrojó como resultado "que la modalidad de ejecución más eficiente y efectiva para el desarrollo del proyecto es mediante el modelo PPP". Además, el estudio contó con un panel de diez expertos. Lamentablemente ninguno expresó ${ }^{63}$ que la comparación debía hacerse entre PPP y concesión de obra pública (ley 17.520) y no entre PPP y obra pública (ley 13.064), ya que esos contratos PPP viales eran mucho más parecidos a una concesión que a una obra pública.

Cabe agregar que la Subsecretaría PPP informó que en caso de afrontarse la obra con recursos públicos el proyecto habría iniciado en el 2023 "con los costos sociales que la demora del proyecto genera”. ¿Por qué al 2023? No se sabe, debió tratarse de una fecha arbitraria. De todos modos, al 2021 esos proyectos PPP no se ejecutaron, por lo que el costo social de los contratos PPP viales fue a todas luces muy alto. Por otra parte, si se considerase que las obras viales están ligadas a la seguridad, a eso habría que añadirle un costo humano.

La Comisión se reunió en cinco ocasiones. O en tres (todas en 2018) si se descontase la reunión constitutiva y la de 2019

62 Por otro lado, en el segundo informe presentado por la Subsecretaría PPP a la Comisión a en enero directamente explicitó que en análisis comparativo se hacía en términos de "PPP vs. Obra pública".

630 no constó, o así no lo expresó la Subsecretaría PPP en ese informe. 
(única de ese año) que fue solo informativa, pues no se contó con quórum. En la reunión del 9 de octubre de 2018 se dio cumplimiento a la última parte del artículo 30 de la ley de contratos PPP, que estipula que el titular de la unidad PPP debe concurrir una vez por año a la Comisión a brindar un informe sobre el estado de ejecución de contratos en curso y respecto a proyectos previstos para los próximos dos ejercicios presupuestarios. Pese a que aquel funcionario estuvo presente en la reunión, la presentación principal estuvo a cargo del entonces Ministro de Transporte de la Nación, Guillermo Dietrich.

El Ministro expuso durante varios minutos. Tanto las diapositivas $^{64}$ como la versión taquigráfica ${ }^{65}$ se pueden consultar en internet. De la presentación se destaca, primero, que los contratos PPP viales, etapa 1, están enmarcados "en el Plan de Infraestructura y Transporte". Aunque corresponde aclarar que la diapositiva en cuestión afirmaba que se trataba del plan "más ambicioso de la historia del país".

El Ministro también dijo que la modalidad PPP ha sido una de las "más exitosas para desarrollar infraestructura en muchísimos países del mundo" y que "se cumplen mejor los plazos que en los sistemas de obra pública tradicional”. Afirmó que los contratos PPP viales (seis corredores) de la etapa 1 ya estaban suscriptos (se firmaron el 31/7/2018) y que se esperaba que prontamente comenzase la ejecución de las obras. Nota reveladora: técnicamente nunca comenzaron. Además, Dietrich anunció la segunda etapa de contratos PPP viales, que abarcaría diez corredores más por una extensión de más de dos mil kilómetros.

A continuación, tuvo la palabra José Luis Morea, titular de la Subsecretaría PPP quien explicó el esquema de los contratos PPP viales (a repasarse más abajo) y señaló que el financiamiento al corto plazo estaba comprometido por "la llamada

\footnotetext{
64 Ver: https://www.hcdn.gob.ar/export/hcdn/comisiones/especiales/cbscppp/Presentaciones/ PresentacionMinistrodeTransporteGuillermoDietrich9-10-2018.pdf.

65 Ver: https://www.hcdn.gob.ar/export/hcdn/comisiones/especiales/cbscppp/reuniones/ vt/VTBic.-Seguimiento-de-Contratos-dePPP.pdf.
} 
causa de los cuadernos". No obstante, anunció que se crearía un nuevo fideicomiso individual especialmente dedicado a "canalizar estos recursos que hoy están trabados en la banca local e internacional”. Así, Morea confirmó lo que hasta el momento era especulación periodística: los contratos PPP que serían financiados por privados finalmente serían financiados por el Estado $^{66}$. Pero eso no es lo más curioso, sino que Morea justificó la medida en nombre de la integridad y la transparencia.

Más adelante, el Senador Carlos Caserio le preguntó al Ministro qué pasaría con los contratos PPP viales adjudicados ante el aumento reciente del "riesgo país" (por esos días apenas arriba de los 600 puntos), puesto que de ese índice dependía el financiamiento de los proyectos. El Ministro respondió: "Claramente, en el entorno de riesgo país en el que estuvimos semanas anteriores no hay una colocación posible, por lo tanto, hacer un número ahí es hacer fantasía porque en ese entorno, el mercado no financia estas colocaciones. Pero sí hemos dado un plazo suficiente previendo que siempre puede haber un acontecimiento, de forma tal que hay tiempo más que suficiente para esta colocación". Ese tiempo era un plazo de doce meses, que fue prorrogado en 2019 cuando el riesgo país superaba los 2000 puntos y que venció en noviembre de 2020.

Por otro lado, la Comisión suscribió un acuerdo de cooperación $^{67}$ con la Oficina de Presupuesto del Congreso (OPC), órgano desconcentrado y técnico creado por ley 27.343. La OPC elaboró dos informes acerca de los contratos $\mathrm{PPP}^{68}$, uno en

\footnotetext{
66 A su vez, en dicha reunión se fundamentó la medida en los artículos 4 y 9 de la ley 27.328. Sin embargo, allí se alude a "facilitar el acceso al mercado de capitales" (artículo 4 inciso j) y a "facilitar las condiciones de su financiamiento" (artículo 9 inciso b). ¿Facilitar el acceso y/o las condiciones implican proveer el financiamiento? Parecería que no. De todos modos, el artículo 60 de la ley 27.467 (presupuesto 2019) creó el “Fideicomiso Marco de Asistencia Financiera para la Obra Pública Argentina".

67 Ver: https://www.hcdn.gob.ar/export/hcdn/comisiones/especiales/cbscppp/doumentacion/ConvenioMarcoCBPSCPPPyOPC.pdf.

68 Ambos disponibles aquí: https://www.opc.gob.ar/categoria/otras-publicaciones.
} 
diciembre de 2018 y otro en marzo de 2020. En el primero, la OPC señaló que "frente al incremento del costo de financiamiento, a fin de diciembre de 2018 el gobierno decidió suspender temporariamente los llamados a licitación de nuevos proyectos PPP, hasta tanto se observe una reducción en el riesgo país". Y que "las agencias calificadoras de riesgo consideran que la calidad crediticia de las obligaciones de pago del fideicomiso está estrechamente vinculada al Estado Nacional, precisamente debido a la asignación de recursos tributarios y al compromiso del aporte contingente por parte del Tesoro".

En el segundo informe de marzo de 2020 la OPC indicó que no había más proyectos adjudicados por modalidad que los contratos PPP viales de la Etapa 1 y que, al 31/10/2019, apenas mostraban un $1,18 \%$ de avance y se habían emitido títulos -en concreto, TPI- por más de 112 millones de dólares.

\section{Los proyectos PPP viales}

Tal como se comentó, en junio de 2018 la DNV dispuso las adjudicaciones de la licitación pública del Proyecto denominado "Red de Autopistas y Rutas Seguras. Proyecto PPP Vial - Etapa 1. Ley 27.328. Corredor Vial A, B, C, E, F y Sur". Entre los adjudicatarios se encontraban muchas empresas históricamente ligadas a la obra pública nacional. Cada uno de esos contratos PPP viales fue licitado por montos superiores a los 700 millones de dólares. El costo total de los seis contratos adjudicados fue previsto por la DNV en más de 5.300 millones de dólares, aunque su costo financiero final iba a superar los 8 mil millones de dólares.

La fijación de precios en dólares fue una de las supuestas pautas de "previsibilidad" que brindarían los contratos PPP en cuestión, aparte de la inaplicabilidad -fijada por la propia ley 27.328- de los regímenes de obra pública, de concesión de obra pública, de contratos de la Administración Pública Nacional, de expropiaciones y de responsabilidad del Estado. Una ley al margen de la ley. 
Ahora bien, como se precisará más abajo, la fijación de esos componentes dolarizados no recibió justificación alguna en el procedimiento constitutivo de los contratos, sin perjuicio de la ya mencionada ventaja informada por los funcionarios y políticos que defendían esta modalidad de contratación.

La "Red de Autopistas y Rutas Seguras - Etapa 1" iba a consistir en su primera en seis corredores estratégicos que atraviesan las provincias de Buenos Aires, Santa Fe, Córdoba, La Pampa, San Luis y Mendoza. Las obras, según información provista por el propio Ministro de Transporte Guillermo Dietrich ${ }^{69}$, implicarían 3.300 kilómetros $(\mathrm{km})$, de los cuales $800 \mathrm{~km}$ serían de autopistas (en rigor, rutas con dos carriles en cada sentido) y $1.600 \mathrm{~km}$ de rutas seguras (rutas en las que cada tanto aparece un tercer carril para permitir sobrepasos). Iban a generar más de 23.000 puestos de trabajo.

En las licitaciones se recibieron treinta y dos ofertas de diez consorcios, de los que siete eran argentinos. Se informó que, asimismo, aquellas licitaciones cumplieron con altos estándares de transparencia y participación y se hizo énfasis en la gratuidad de pliegos y la digitalización de procedimiento.

En octubre de 2018 las adjudicatarias ya habían integrado más de 550 millones de dólares en concepto de garantías, a saber: de mantenimiento de oferta, de servicios principales, de obras principales y de cierre financiero. Esta última debía incrementarse (de 2 a 2,5 y finalmente a 3\%) si se acercase la fecha de vencimiento para obtener el cierre financiero (julio de 2019, luego se prorrogó por Adendas). Sin embargo, y contra la propia esencia de los contratos $\mathrm{PPP}^{70}$, el Estado Nacional iba a proveer una fuente financiamiento para el "corto plazo" compuesta con aportes de bancos privados, organismos internacionales de crédito y del Banco Nación, más aportes presupuestarios, letras del

\footnotetext{
69 Ver notas 64 y 65.

70 Es decir, obtener los fondos, propios o de terceros (cierre financiero), suficientes para cumplir con el resto de sus obligaciones y, en concreto, para ejecutar las obras.
} 
tesoro y las propias garantías. Un Frankenstein financiero para que arrancasen las obras.

El "repago", es decir la forma en que se pagarían estos proyectos, dependería de los aportes del SISVIAL por recaudación de impuesto al gasoil y de peajes ${ }^{71}$. Si hiciera falta, se acudiría a aportes del Tesoro o asignaciones "contingentes" presupuestarias ${ }^{72}$.

Siempre evito citar definiciones del diccionario, pero en este caso me resulta inevitable compartir la de "repagar": "pagar caro algo" ${ }^{\prime 3}$.

A su vez, el "repago" de obras ocurriría desde 2020, en veinte cuotas semestrales durante diez años. Es decir que, en teoría, el pago se consumaría una vez terminada la obra financiada por el privado, pero por el momento solo financiada por el propio comitente. La titulación -la emisión de títulos, títulos por inversión (TPI)- en el caso de las obras acaecería de manera trimestral y consistiría en "certificados incondicionales, autónomos e irrevocables de reconocimiento de inversión trimestral", "emitidos al alcanzar hitos temporales" ${ }^{74}$. La autoridad contratante certificaría el avance de obras por "actas de reconocimiento de avance de inversión" (ARAI) y cada tres meses se expedirían los TPI -denominados en dólares- por un valor proporcional del "Monto Total Requerido TPI" (MTRTPI).

\footnotetext{
71 Peajes a integrar a fondos de "repago": solo de los corredores E y Sur.

72 Según la OPC: “En su dictamen previo al Ilamado a licitación, el Ministerio de Transporte, en su carácter de autoridad convocante, determinó que el flujo de fondos provenientes del impuesto a los combustibles será suficiente para hacer frente a las obligaciones contraídas por el Fideicomiso. Bajo ese supuesto, no sería necesario que el Tesoro efectúe ningún aporte adicional para cubrir los pagos de los TPI. Sin embargo, dicho documento no contiene los montos de recaudación estimados ni incluye la metodología de estimación respectiva. De acuerdo a un estudio privado, en cambio, los recursos asignados al fideicomiso serían suficientes sólo hasta 2022, y a partir del año siguiente deberían ser complementados con un aporte adicional del Tesoro".

Ver: Informe sobre "Impacto fiscal de los proyectos de participación público privada", OPC, p. 32.

73 Diccionario de la lengua española, ver: https://dle.rae.es/repagar?m=form.

74 Ver nota 64.
} 
¿Cuál sería ese monto? Según la OPC, "el MTRTPI de cada corredor vial fue determinado como parte del proceso licitatorio, pero está sujeto a un ajuste por riesgo país, a realizarse a la fecha de cierre financiero" 75 . A fines de 2018 ese monto total superaba los 9 mil millones de dólares ${ }^{76}$. No se sabía cuánto iban a costar los proyectos, pero sí que se pagarían en dólares. Y que saldrían caros, por supuesto.

En paralelo, estos proyectos viales a realizarse por contratos PPP envolverían otras contraprestaciones para los contratistas: por tránsito (tarifa de peaje a abonar por usuarios de cada corredor), por exceso de carga (según tarifa por ese concepto), por explotación comercial (de terceros o propia de servicios accesorios) y por disponibilidad (operación y mantenimiento) ${ }^{77}$. Esta última se pagaría mediante títulos por disponibilidad (TPD) y se vincularía al mantenimiento y operación de cada corredor. Los fondos surgirían de misma manera que la prevista para los TPI pero los TPD se emitirían con otra frecuencia (mensual) y en pesos.

No obstante, aún no quedaba claro qué es lo que se iba a pagar.

75 La OPC explica que: "Dado que los TPI no devengan intereses, los montos ofertados y adjudicados incluyen de manera implícita el costo financiero asociado, que debido la ubicación de los proyectos está directamente vinculado con el riesgo soberano. Al ser responsables de la obtención del financiamiento para los proyectos, los contratistas se encontrarían expuestos a cambios en el riesgo soberano entre la fecha de presentación de la oferta (cuando estimaron el costo financiero que afrontarían) y la fecha en que logran el cierre financiero (cuando queda efectivamente determinado el costo financiero del proyecto). Para repartir este riesgo con el sector público y reducir así la incertidumbre en la etapa de planificación y análisis de los proyectos, los contratos contemplan un ajuste al MTRTPI asociado al cambio que haya tenido la brecha de rendimiento promedio entre los bonos de Argentina y los EEUU". Ver: Informe sobre "Impacto fiscal de los proyectos de participación público privada", OPC, p. 23.

76 Informe sobre "Impacto fiscal de los proyectos de participación público privada", OPC, p. 19.

77 Definida en los contratos PPP viales como "la contraprestación por la prestación de los Servicios Principales durante dicho periodo de disponibilidad". A su vez, "periodo de disponibilidad" es determinado como "cada periodo sucesivo de un mes contado a partir de la fecha de comienzo de los Servicios Principales". 


\section{Problemas de transparencia y sustentabilidad de los proyectos PPP viales}

En agosto de 2018 el Diputado José Luis Gioja presentó ante la DNV un pedido de acceso a la información pública para que el organismo precise el monto de cada uno de los ítems, renglones y/o rubros de los contratos adjudicados -en junio de 2018- de los corredores viales A, B, C, E, F, y Sur ${ }^{78}$. La DNV contestó que todas las actuaciones habían tramitado en un expediente que estaba disponible para su consulta en la mesa de entradas del organismo y que, asimismo, los datos se encontraban en su sitio de internet.

Pese a que la DNV debió proporcionar datos concretos, la información requerida tampoco estaba publicada en aquella página de internet. Gioja entonces presentó un reclamo por incumplimiento ante la Agencia de Acceso a la Información. A fines de diciembre de 2018, la Agencia contestó que, toda vez que el organismo puso a disposición la información faltante, correspondía proceder al archivo de las actuaciones. Pero esa información brindada por la DNV solamente consistía en un cuadro con las adjudicaciones de los corredores viales y los montos totales de cada contrato, sin la discriminación peticionada.

En febrero de 2019 Gioja interpuso una acción judicial por denegatoria de acceso a la información pública (expediente $\left.\mathrm{n}^{\circ} 5171 / 2019\right)^{79}$. La DNV contestó la demanda y lo hizo con una respuesta aún más sorprendente: citó una nota interna del organismo -es decir jamás publicada ni notificada- en la que se consignaba que las licitaciones en cuestión no preveían la cotización por cada uno de los ítems, renglones y/o rubros. En otras palabras, la DNV sostuvo que había licitado sin detalle alguno y por montos globales obras de más de 5.300 millones

\footnotetext{
78 Primera aclaración: algunos párrafos de este apartado ya fueron publicados en Acceso a la información pública y contratos PPP, El Cohete a la luna, 3/11/2019, disponible en https:// www.elcohetealaluna.com/otra-derrota-del-secretismo-oficial, otro texto de mi autoría.

79 Segunda aclaración: con mi patrocinio jurídico.
} 
dólares. Esto escapó a la Jueza de Primera Instancia, quien aceptó la postura de la DNV y rechazó la acción.

En segunda instancia las opiniones no favorecieron a la DNV. Tomó intervención el Fiscal de la Cámara, quien apuntó que de los pliegos de las contrataciones surgía que los adjudicatarios debían proveer el cómputo métrico de cada uno de los ítems en sus respectivos proyectos ejecutivos. La Sala I de la Cámara en lo Contencioso Administrativo Federal se apoyó en aquel dictamen y admitió la acción de Gioja, dado el -finalmente detectado- incumplimiento imputable a la DNV en materia de acceso a la información pública.

La sentencia de segunda instancia impuso, además, que la DNV provea en diez días toda documentación de la cual pudiesen extraerse los datos vinculados a la información solicitada sobre el detalle de costo de cada ítem de los contratos PPP adjudicados.

En diciembre de 2019 la DNV puso la supuesta información a disposición del Diputado Gioja. Sin embargo, de la información provista por la DNV únicamente surge que se realizó una licitación en la que solo se consideraron los montos globales de cada corredor vial ${ }^{80}$. Existirían elementos para dar con los datos requeridos, por ejemplo los proyectos ejecutivos (que contendrían algún tipo de cómputo métrico) a confeccionar por los contratistas $^{81}$. Pero estos no fueron entregados en sede judicial ni se publicaron en internet.

80 En los Pliegos de bases y condiciones particulares (denominado PLIEG-2018-04494692APN-PYC\#DNV para el corredor vial A) de los seis corredores no se impuso cotización de la oferta económica por ítem, renglón o rubro, solo el monto total requerido TPI. Además, se fijó como criterio de selección de oferta más conveniente la que expresase "menor monto anual en dólares que se solicita percibir en el año 2025 por pagos por inversión en el corredor vial". Disponible en https://www.argentina.gob.ar/sites/default/files/pliego_de_bases_y_condiciones_particulares_a.pdf.

81 En el Pliego de especificaciones técnicas generales se alude en el artículo 41 que "cada Proyecto Ejecutivo aprobado deberá contener el cómputo métrico de cada uno de los ítems que integran cada obra principal". En este Pliego también se estipuló que la confección y presentación del proyecto ejecutivo estaría a cargo del contratista. Disponible en https:// 
Así, no se conoce -ni se pudo conocer- con precisión la composición de costos de los contratos PPP viales.

No obstante, a partir de la revisión de toda la documentación sobre contratos PPP viales que entregó la $\mathrm{DNV}^{82}$ se descubrieron otras falencias vinculadas a la transparencia y la sustentabilidad de esos proyectos.

Primero, se destaca que en los antecedentes de las contrataciones no aparece justificación alguna a la fijación de valores y formas de pago en dólares estadounidenses. Dados los sucesos financieros y cambiarios que atravesó el país desde la suscripción de esos contratos, es evidente que sería muy difícil afrontar los compromisos estipulados en esa moneda.

En el "Informe preliminar Corredores Viales Nacionales Etapa 1" (documento denominado "IF-2017-24360223-APN-PYC\#DNV" de fecha 17/10/2017), se había estimado la inversión en obras de los primeros cuatro años en la suma de $\$ 94.640$ millones de pesos. Y un costo de $\$ 176.767$ millones de pesos por el total. También se discriminaban los montos por corredor vial, siempre en pesos. En fecha 23/11/2017 la DNV emitió otro informe sobre el efecto financiero y presupuestario de los contratos en los que, al igual que en el antecedente, se indicaban solo montos en pesos ${ }^{83}$.

Al día siguiente el Ministro de Transporte elaboró el dictamen previsto en el artículo 13 de la ley de contratos PPP, en

ppp.vialidad.gob.ar/wp-content/uploads/2017/12/PLIEGO-DE-ESPECIFICACIONES-TECNICAS-GENERALES.pdf.

En los anexos III y IV de los Pliegos de especificaciones técnicas particulares se prevé cómo deberían integrarse los cómputos métricos y cómo se realizarían las mediciones de obras, para lo que se remite al respectivo proyecto ejecutivo, que a su vez debería incluir la incidencia porcentual de cada ítem sobre el total de la obra.

82 La DNV hizo entrega de tres discos DVD que contenían más de 500 archivos, varios de centenares de páginas, algunos de miles. Si se quisiera acceder a la información, puede solicitarla al correo electrónico indicado al inicio.

83 IF-2017-29614304-APN-DNV\#MTR (23/11/2017). Informe del Coordinador General de la DNV, Jorge Rubén del Pup, sobre "Estimación del efecto financiero y presupuestario del contrato por los ejercicios presupuestarios durante los cuales será ejecutado". 
el que se contemplaron montos y costos en $\operatorname{pesos}^{84}$. Pero en el apartado de análisis económico y financiero aparecieron por primera vez y sin explicación valores en dólares ${ }^{85}$. Esto es llamativo, además, porque este dictamen es muy parecido al "Informe preliminar”. Se innovó en la moneda sin razón explícita.

Por lo tanto, las primeras proyecciones se realizaron en pesos y luego se pasaron -en parte, solo para los TPI- a dólares. Esto implicó una distorsión para la evaluación de impacto en resultados fiscales, los efectos financieros y presupuestarios y la estimación de la suficiencia de flujo de recursos públicos. Es decir que el dictamen no cumplió ni podía cumplir con los recaudos de los incisos b, c y d del artículo 13 de la ley 27.328.

En paralelo, dicho dictamen tampoco expuso las razones por las que el interés público se vería mejor atendido con un contrato PPP que con un contrato celebrado por las leyes 13.064 o 17.520, según demanda el inciso a del artículo 13 de la referida ley. Y no abordó la "evaluación de costo-beneficio respecto del recurso a esta modalidad contractual, considerando los riesgos en caso de extinción del contrato" (inciso h).

De esta forma, el dictamen emitido por la autoridad convocante no obedeció a lo dispuesto por ese artículo 13 de la ley de contratos PPP. Ni siquiera a la "Guía metodológica para la elaboración del dictamen del artículo 13 de la ley 27.328"86.

\section{Contratos PPP viales - Cuestiones salientes, cierre financiero y riesgos}

En el ya citado informe de 2018 la OPC enumeró posibles inconvenientes de los contratos PPP que resultarían en mayores costos finales: un análisis costo-beneficio poco riguroso por

\footnotetext{
84 IF-2017-29871632-APN-MTR (24/11/2017), página 191. El dictamen se puede consultar aquí: https://ppp.vialidad.gob.ar/wp-content/uploads/2017/11/Dictamen-Art13-27328-MT-PPPVIAL-E1.pdf. 85 Ver páginas 204 y 465 del dictamen.

86 Disponible en https://www.argentina.gob.ar/sites/default/files/guias_metodologicas_v6_0.pdf.
} 
parte del sector público, costos de financiación de los proyectos superiores para las empresas privadas que para el sector público, renegociaciones por marcos normativos mal diseñados y mayores costos por terminación anticipada de contratos ${ }^{87}$. Desafortunadamente, sabemos que se dieron los dos primeros puntos. Veamos qué ocurrió con los demás, para lo que hay que abordar en general los contratos PPP viales ${ }^{88}$.

En primer lugar, en el artículo 1 de los contratos PPP viales se encuentran ${ }^{89}$ las 248 definiciones, entre las que se destacan "ARAI", "cierre financiero", contraprestaciones varias y "contrato de cobertura recíproca" $"$.

El cierre financiero significa que el contratista financie el cumplimiento de sus obligaciones con endeudamiento (crédito $)^{91}$, todo ello según diferentes variantes, según el artículo 1 , puntos 48 y 94 . O, en otras palabras, que el contratista demuestre

87 Informe sobre "Impacto fiscal de los proyectos de participación público privada", OPC, p. 5. Por otro lado, el Observatorio de Contratos de Participación Público Privada de la Universidad Nacional de José C. Paz (UNPaz) postuló en 2018 otros potenciales problemas de los proyectos y contratos PPP, a saber: "falta de competencia privada y concentración en la asignación de proyectos; extensión en las negociaciones pre-contractuales; demoras considerables en la ejecución contractual con ineficiencias y asunción de costos adicionales por la parte pública para terminar obras; exceso de optimismo traducida en indebida diligencia previo a la contratación de los PPP". Ver: "Informe sobre contratos de participación público privada", Observatorio de Contratos de Participación Público Privada, UNPaz, 2018, p. 7. Disponible en https://cjys.unpaz.edu.ar/sites/default/files/Tercer\%20Informe\%20PPP\%20 -\%20Agosto\%202018\%20[Final].pdf

88 Cada uno tiene más de cien artículos y más de ciento cincuenta páginas. Disponibles para su consulta aquí: https://www.argentina.gob.ar/jefatura/ppp/contratos-registrados.

89 Se utilizará el presente para la descripción de los contratos PPP viales, pero bien se podría emplear el pasado, pues han sido extinguidos.

90 "Contrato de cobertura recíproca" significa "el contrato de compensación recíproca por variaciones en el tipo de cambio real al celebrarse entre el Fideicomiso RARS PPP actuando no a título personal sino exclusivamente en su carácter fiduciario y el Contratista PPP que haya solicitado su suscripción en la oferta adjudicada". Fueron suscriptos en julio de 2018 y se reconoció una banda de variación de hasta del 10\% para el tipo de cambio de referencia y la unidad de valor adquisitivo.

91 Que se puede acreditar de distintas formas, siempre fijando como pauta el compromiso de entidades financieras por el total o una porción de los títulos a emitirse y/o adquirirse. 
-en alguna medida, tomando como referencia el MTRTPI- financiamiento para cumplir con los compromisos asumidos en el respectivo contrato ${ }^{92}$.

En el artículo 6 se define el objeto de la siguiente manera:

"El contrato PPP tiene por objeto el diseño, construcción, ampliación, mejora, reparación, remodelación, operación, mantenimiento y explotación comercial del Corredor Vial con sujeción al marco regulatorio PPP. El contrato PPP comprende la obligación del Contratista PPP de finalizar las Obras del contratista PPP, prestar los Servicios Principales y cumplir con sus demás obligaciones establecidas en el Contrato PPP".

En el artículo 12 se hallan las obligaciones del contratista, entre las que están las de confeccionar y preparar el proyecto ejecutivo, alcanzar el cierre financiero antes de la fecha programada y constituir las garantías correspondientes.

El plazo de los contratos se fijó por quince años (artículo 14), aunque las obras principales deberían ejecutarse desde la fecha de toma de posesión inicial (artículo 16), lo que ocurrió en 2018 para los seis corredores viales.

Se estipulan regímenes específicos de obras (artículo 37 y subsiguientes), servicios (artículo 45), contraprestaciones (artículo 46 y ss.), garantías (artículo 58 y ss.) y ecuación económico-financiera (artículo 68 y ss.) ${ }^{93}$.

\footnotetext{
92 La explicación de la OPC es de las más claras: "el contratista deberá suscribir los contratos que acrediten la obtención del financiamiento necesario para llevar a cabo el proyecto. El contratista tiene un plazo de 6 meses desde la suscripción del contrato para lograr el cierre financiero, el cual podrá ser prorrogado por hasta dos períodos de 3 meses. Para ello, el contratista podrá financiarse con deuda o capital propio. En el primer caso, el monto del endeudamiento debe ser por un mínimo equivalente al 54\% del monto total requerido TPI, con un compromiso de aporte de capital del 6\%. Si, en cambio, el contratista opta por financiarse exclusivamente con capital propio, el aporte de capital comprometido deberá ser equivalente al $60 \%$ del monto total requerido TPI". Ver: Informe sobre "Impacto fiscal de los proyectos de participación público privada", OPC, p. 21.

93 Por cierto, se admiten ajustes por inflación o por falta de incremento de valores de tránsito para la contraprestación por disponibilidad (artículo 71).
} 
Se prevén diversas causales de extinción del contrato: incumplimiento de cierre financiero ( $s i$ el contratista no lo hubiese alcanzado a la fecha programada, artículo 85), mutuo acuerdo (artículo 87), culpa del ente contratante (artículo 88, supuesto en el que debería abonar al contratista el pago por inversión no amortizada -calculado en dólares- y el pago por extinción, más intereses) y culpa del contratista (artículo 89, por ejemplo por no renovar garantías o no ejecutar obras, casos en los que debería abonar una penalidad y se ejecutarían garantías).

Por otro lado, los contratos se podrían extinguir por razones de fuerza mayor, lo que implicaría un evento de naturaleza indeterminada y conllevaría que el contratante cubra un pago de inversión no amortizada (más intereses) para el contratista, sin perjuicio del pago de los TPI y TPD que hubieran sido emitidos con anterioridad (artículo 90).

También por razones de interés público, aunque "el ejercicio de esta facultad estará limitado a casos excepcionales de magnitud extrema" (artículo 9.7) y "producirá los mismos efectos que la extinción del contrato PPP por causal atribuible al ente contratante" (artículo 91).

Asimismo, como se señaló, los contratos PPP viales consignaron un procedimiento de solución de controversias. Se prescribieron los mecanismos de "negociaciones amistosas" (artículo 95), "panel técnico" (artículo 96) y, si los anteriores se hubieren transcurrido sin éxito y nunca antes, el "arbitraje" (artículo 97).

En paralelo, cabe recordar que es la ley de contratos PPP la que en su artículo 9 inciso b prescribe que los contratos deberán contener previsiones sobre el "equitativo y eficiente reparto de aportes y riesgos entre las partes del contrato... de modo tal de minimizar el costo del proyecto y facilitar las condiciones de su financiamiento" ${ }^{94}$.

\footnotetext{
94 Mairal y Veramendi opinan que: "Así se prevé una equitativa y eficiente asignación de riesgos entre las partes, según cuál de ellas se encuentre en mejores condiciones para
} 
En cuanto a la "Asignación de riesgos" de los contratos PPP viales, aquella está fijada en el artículo 67, que, a su vez, remite al Anexo A sobre "Matriz de riesgos". Por cierto, la Matriz estuvo disponible para su consulta antes de la presentación de ofertas. De hecho, durante la convocatoria se hicieron observaciones y consultas al modelo de contrato y a los pliegos que derivaron en modificaciones de aquellos.

En aquella Matriz, se apuntan como riesgos asignados al "privado" (es decir al contratista) los siguientes: riesgo de la demanda (por cantidad de tránsito "pagante"), riesgo de aumento de costos por inflación y riesgo del cierre financiero. Respecto al cierre financiero se detalla que el contrasita asume el riesgo de:

- disponibilidad de financiamiento en los mercados de deuda nacionales e internacionales para alcanzar el cierre financiero en el plazo requerido, y, al mismo tiempo, se aclara que aquel debe ser suficiente para ejecutar las obras principales;

- cumplir con los requisitos solicitados por entidades financieras;

- "cambios en la situación de los mercados financieros que dificulten la obtención de financiamiento", para lo que se "prevé un plazo razonable para alcanzar el cierre financiero, que puede ser extendido a opción del contratista hasta doce meses".

prevenirlos, asumirlos o mitigarlos, incluyendo expresamente, entre otros riesgos, el hecho del príncipe y el alea económica extraordinaria". Ver: MIRAL, Héctor .A. - VERAMENDI, Enrique V., op. cit.

Por otro lado, Stortoni expresa y se pregunta lo siguiente: “Es interesante que se pretenda construir un sistema contractual, con asunción de riesgos que sean equitativos. Es justo que esos riesgos sean asumidos por el privado y el Estado. Y es más inteligente que sean obligaciones de calidad las que se exijan para ejecutar estas obras. Que no sea un mero negocio financiero, ocasional o especulativo depende de lo que falta: ¿cómo hacer un buen modelo contractual de PPP?". Ver: STORTONI, Gabriela (2017). "Participación Público Privada en Argentina" en Revista Vial, $n^{0}$ 116, 7/9/2017. 
Todo parecía estar claro. Se precisaban los riesgos y se estipulaba quién debía asumirlos. Sin embargo, en julio de 2019, a un año de las suscripciones de los contratos PPP viales, se firmaron "Adendas" para cada uno de ellos" por contratos mal diseñados? Aquí están.

Según la DNV, las modificaciones introducidas en cada Adenda abarcaron lo siguiente: plazo para alcanzar el cierre financiero, porcentaje de garantía de cierre financiero, plan de obras principales, plazos para cumplimiento de obras complementarias a las estaciones de cobro, y de otras obras y la definición del Monto Total Requerido TPI ajustado. Y sobre el cierre financiero la Adenda establece un nuevo plazo para alcanzarlo hasta fines de noviembre de $2020^{96}$.

Sucedió que en julio de 2019 las condiciones para que los contratistas obtuviesen financiamiento eran similares o peores a las de 2018. Pero el plazo del cierre financiero estaba por vencer. Y pese a que los adjudicatarios -casi todos avezados contratistas de la Administración- habían asumido los mencionados riesgos, se firmaron las Adendas ${ }^{97}$. La DNV justificó las modificaciones en el interés público y la realización de las obras ${ }^{98}$. No obstante, ya se sabía que con esas condiciones económicas-financieras -que después empeoraron- los contratos PPP viales eran inviables.

\footnotetext{
95 Se pueden consultar en https://www.argentina.gob.ar/jefatura/ppp/contratos-registrados. 96 Respuesta de la DNV a un pedido de acceso a la información pública, Providencia PV2019-98815796-APN-RRIICP\#DNV, correspondiente a expediente EX-2019-87133762- -APNDNAIP\#AAIP, 4/11/2019.

97 Cuando las modificaciones benefician a los contratistas nadie se queja por la "seguridad jurídica". A su vez, los contratos PPP viales se limitan en su artículo 102 a establecer que: “El contrato PPP sólo podrá ser modificado mediante documento escrito otorgado por ambas partes".

98 También se motivó la decisión en que había ocurrido un "evento de crédito" para postergar la fecha de cierre financiero. El "evento de crédito" era determinado por la brecha entre el rendimiento de bonos argentinos y el bono de EE.UU. A todo ello, se le añade que en el Anexo D de los contratos PPP viales se prevé que a la fecha de cierre financiero se ajustaría el MTRTPI y los componentes para definir esa corrección depende de la anterior brecha. Esto último es lo que termina elevando el costo financiero total y el aumento del MTRTPI.
} 
Había que decidir cómo se extinguían los contratos, no cómo se modificaban. Lo que no se quería hacer era asumirlo a pocas semanas de las elecciones nacionales ${ }^{99}$.

Cabe destacar que la situación se había vuelto incómoda para ambas partes. Si bien los riesgos de financiamiento habían sido asumidos por los contratistas, los mayores costos se hubieran trasladado al contratante ${ }^{100}$. El costo financiero total ya superaba en 2020 los 10 mil millones de dólares, es decir casi el doble -o más- de los costos totales contemplados para los seis corredores (5.300 millones de dólares) ${ }^{101}$. Por eso, solo se podía postergar el final, de ninguna manera evitarlo. Pero el Estado debe funcionar de manera eficiente. Esto supone evitar mayores costos por modalidades contractuales improcedentes, por supuesto, $\mathrm{y}$ fomentar que las obras comiencen lo antes posible.

Así, se puede afirmar que los contratos PPP viales implicaron también mayores costos por su terminación anticipada. Eso se puede aseverar sin perjuicio del modo en que fueron extinguidos, ya que, a fin de cuentas, siempre existirá un costo irrecuperable que consistirá en los tres años -2018 a fines de 2020- que se perdieron con contratos PPP viales que no tenían posibilidad

Las primarias abiertas, simultáneas y obligatorias (PASO) se celebraron el 11 agosto de
2019. El 12 de agosto el riesgo país se duplicó (pasó de 861 a 1658 puntos). La cotización
del dólar subió de 46,55 a 57,3 pesos. Según Esteban Lafuente, el salto del tipo de cambio
acumulado en 2019 año superó el $62 \%$. Ver: Dólar 2019. El día dramático, el récord histórico,
devaluación del $38 \%$ y la vuelta del cepo, Diario La Nación, 31/12/2019, firmada por Esteban
Lafuente, disponible en https://www.lanacion.com.ar/economia/dolar/dolar-2019-el-dia-dra-
matico-record-historico-nid2320076.

100 Ezequiel Cassagne expresa sobre las Adendas: "Esta modificación bilateral de los contratos era necesaria para los contratistas, pues iban a incumplir todos los términos contractuales y quedaban expuestos a la ejecución de las correspondientes garantías, pero también para el propio Estado Nacional, en la medida que si los contratistas obtenían el cierre financiero, en ese momento debían ajustarse los TPI por riesgo país, el cual, al haber incrementado mucho, habría generado un aumento sideral en el costo de los proyectos". Ver: CASSAGNE, Ezequiel (2020). "El régimen de participación público privada en Argentina" en Anuario Iberoamericano de regulación, Universidad Externado de Colombia, Asier, p. 633.

101 Según la OPC, en marzo 2020 ya superaba los 13 mil millones de dólares. Ver: Informe "Seguimiento del Programa PPP", OPC, 2020, p. 7. 
alguna de éxito ${ }^{102}$. Tres años, por cierto, en los que prácticamente no se hicieron obras en ninguno de los seis corredores viales. Y no hay que olvidar que la modalidad PPP supuestamente tenía como ventaja una rápida ejecución de las obras más allá las de las posibles limitaciones presupuestarias a corto plazo.

\section{Seguimiento y ejecución de los contratos PPP viales}

En noviembre de 2019 la DNV informó que los contratistas PPP viales habían integrado las garantías de cierre financiero, servicios principales y obras principales por más de 500 millones de dólares. También la DNV señaló que el 1 de agosto de 2018 se habían suscripto las Actas de toma de posesión inicial y que el plan de obras principales había comenzado -en todos los casos- entre diciembre de 2018 y febrero 2019.

Asimismo, la DNV indicó que entre agosto de 2018 y septiembre de 2019 se habían emitido TPD (por contraprestación por disponibilidad) por 538 millones de pesos y TPI (por contraprestación por inversión) por 79,5 millones de dólares ${ }^{103}$. A fines de octubre de 2019 los TPI emitidos superaban los 112 millones de dólares.

Y, según la OPC, al momento de suscribirse las Adendas el avance promedio de las obras era de un $0,35 \%$ del total, mientras que el previsto en los contratos originales para esa fecha era del 3,36\%. En octubre de 2019 el avance promedio había llegado apenas al $1,18 \%{ }^{104}$.

\footnotetext{
102 En este punto discrepo con quienes el escenario cambió drástica e imprevistamente. Es cierto que al momento de iniciarse las convocatorias de los contratos PPP viales la coyuntura económica-financiera era algo más favorable para estos proyectos, pero en junio de 2018, es decir cuando se realizaron las adjudicaciones, Argentina ya había caído definitivamente en una nueva y profunda crisis, que incluso la había llevado a solicitar el socorro al FMI. En sentido inverso, se puede leer la opinión de Manuel Alderete, quien además escribió y publicó este artículo (citado más arriba) al momento de suscribirse las Adendas. Ver: ALDERETE, Manuel, op. cit.

103 Ver nota 96.

104 Ver: Informe "Seguimiento del Programa PPP", OPC, 2020, p. 12.
} 
En mayo de 2020 se publicaron informes de seguimiento sobre "Avance de obra" y "Servicios Principales" en la página de la Subsecretaría PPP para cada uno de los corredores viales $^{105}$. Los avances de obras (acumulados a mayo 2020) eran los siguientes: corredor A, 1,47\%; corredor $\mathrm{B}, 0,78 \%$; corredor $\mathrm{C}$, $4,13 \%$; corredor E, $0,5 \%$; corredor F, $0,06 \%$; corredor Sur, $1,2 \%$. En promedio, un 1,35\%.

En septiembre de 2020 la DNV informó que no se habían ejecutado garantías de ningún contrato PPP vial ${ }^{106}$. También indicó que a julio de 2020 el avance acumulado era el mismo del párrafo anterior, con excepción del corredor C, que pasó al 4,39\%.

Por otro lado, hasta julio de 2020 se habían emitido TPD por más de 3500 millones de pesos y TPI por más de 140 millones de dólares. Además, los contratistas a agosto de 2020 habían solicitado ajustes de contraprestaciones por más de 2700 millones de pesos $^{107}$.

\section{Los proyectos PPP viales y la pandemia}

Los contratos PPP viales tuvieron su propio capítulo en el marco de la pandemia causada por el coronavirus COVID-19.

En marzo de 2020 la DNV dispuso la suspensión del cobro de la contraprestación por tránsito (peajes) de los seis corredores viales $\mathrm{PPP}^{108}$. La medida fue prorrogada sucesivas veces hasta el 18 de mayo. A su vez, se estableció que los contratistas

\footnotetext{
105 Disponibles en https://www.argentina.gob.ar/jefatura/ppp/contratos-registrados.

106 Respuesta de la DNV a un pedido de acceso a la información pública, Nota N0-2020-61125339-APN-RRIICP\#DNV, correspondiente a expediente EX-2020-55711068-APN-DNAIP\#AAIP, 14/9/2020.

107 Los mismos datos fueron aportados por el Ministerio de Obras Públicas a la Comisión de Obras Públicas de la Cámara de Diputados de la Nación en un informe presentado también en septiembre de 2020.

108 Resolución 98/2020 de la DNV, publicada en el Boletín Oficial en fecha 20/3/2020, disponible en http://servicios.infoleg.gob.ar/infoleglnternet/anexos/335000-339999/335793/ norma.htm.
} 
PPP deberían prestar el servicio de emergencia en la red vial en cuestión y los servicios principales con el objetivo de garantizar el tránsito y la seguridad de los usuarios.

Dos meses más adelante, en mayo de 2020, la DNV determinó que se suspendería el cobro de contraprestaciones por tránsito al personal de salud y fuerzas seguridad hasta que finalizase el aislamiento social, preventivo y obligatorio ${ }^{109}$.

Asimismo, durante la pandemia los contratistas a cargo de los corredores E y F solicitaron medidas cautelares por las que se ordene a la DNV la inmediata devolución de las garantías de obras principales y cierre financiero y la sustitución de la garantía de servicios ${ }^{110}$.

En mayo de 2020 en ambas causas se dictó una medida cautelar ${ }^{111}$ que ordenó a la DNV "que acepte la sustitución de la Garantía de Cierre Financiero y de Servicios Principales por un seguro de caución, por el monto total de las dos garantías en pesos a la cotización del dólar vendedor del BCRA, hasta que se reanuden las tareas correspondientes en la obra en cuestión"112.

109 Resolución 321/2020 de la DNV, publicada en el Boletín Oficial el 29/5/2020, disponible en https://www.boletinoficial.gob.ar/detalleAviso/primera/230002/20200531.

110 Las causas tramitaron en el fuero Contencioso Administrativo Federal como expedientes n 9851 (corredor E) y 9852 (F). Las demandas son prácticamente iguales.

111 Mismo juzgado, casi el mismo texto. En épocas pandémicas los juzgados de feria variaban y a veces parece que funcionaba solo uno de doce.

112 "Corredor Panamericano I SA c/ EN-DNVs/Medida cautelar (autónoma)" y "Corredor Panamericano II SA c/ EN-DNVs/Medida cautelar (autónoma)", expedientes nº 9851 y 9852 de 2020, resoluciones judiciales de fecha $8 / 5 / 2020$. Es menester señalar que el examen de procedencia de la medida cautelar fue cuanto menos temerario y superficial. Y que, como suele ocurrir, el juez no analizó la procedencia según los requisitos previstos en la ley 26.854, sino que se limitó a invocar la verosimilitud del Derecho y el peligro en la demora. La ley 26.854 impone recaudos que parecen ser optativos para los jueces. Por último, el juez consideró suspendidas las obras pese a que no existía acto ni hecho que determinase la suspensión. Resoluciones disponibles en: 1) http://scw.pjn.gov.ar/scw/viewer.seam?id=BuMObcX5IUdXSyKJ10198quarKIzZ8Ntn42mR40IObE\%3D\&tipoDoc=despacho\&cid=2056025; 2) http://scw.pjn.gov.ar/scw/viewer.seam?id=Yaar\%2B4odl5EmNaXqSI23bPrmWTokXVYp4671MWThi64\%3D\&tipoDoc=despacho\&cid=2055754. 
Esto fue apelado por las dos partes. Sin embargo, los derroteros de cada causa luego difirieron.

En la causa del corredor E la medida cautelar fue suspendida por la concesión del recurso de apelación interpuesto contra aquella resolución, conforme a lo previsto por el artículo 13 , inciso 3, de la ley $26.854^{113}$. En la otra causa (corredor F), un juzgado diferente no dispuso ese efecto de la apelación sino el devolutivo. Una ley para todos, un criterio por cada juez ${ }^{114}$.

Por otro lado, en una causa (corredor E) antes de que se pronunciase la Cámara de Apelaciones el contrato fue extinguido, por lo que todo devino abstracto. En la otra (corredor F) sí hubo resolución de segunda instancia y se hizo lugar parcialmente a ambas apelaciones. Se ordenó la devolución y suspensión de garantías de cierre financiero y obras principales y se revocó la sustitución de la garantía de servicios principales ${ }^{115}$. Pero a los pocos días el contrato del corredor en cuestión también sería terminado por acuerdo de las partes.

De todas formas, esta confrontación judicial sirvió para conocer los puntos de vista de cada parte en una época de incertidumbre para los contratos PPP viales. Por lo que corresponde revisar sus argumentos.

En ambas causas judiciales las partes actoras (o la parte actora, singular, pues los escritos son casi idénticos) propusieron una batería de causales en la que se confunden cosas para afirmar una falsa premisa: que existieron eventos de fuerza

\footnotetext{
113 Resolución disponible en http://scw.pjn.gov.ar/scw/viewer.seam?id=UH1ECGEPddmtcyl05fvJDCBbxggOz7EduS3DCdT5B3M\%3D\&tipoDoc=despacho\&cid=2015924.

114 A lo que se podría sumar que en la causa del corredor $F$ el primer juez interviniente se había declarado incompetente siguiendo el dictamen del fiscal, para quien el reclamo, conforme a lo previsto por el respectivo contrato, debía ser conocido por un tribunal arbitral, pese a que los paneles técnicos no se hubieren constituido. Dictamen disponible en http:// scw.pjn.gov.ar/scw/viewer.seam?id=8TRK1VMxpswx3uLw9twGYjg0JPwCo5Zm1SJoeuZ9F08\%3D\&tipoDoc=despacho\&cid=2052426.

115 Resolución disponible en http://scw.pjn.gov.ar/scw/viewer.seam?id=Y1ZT99GQfijOovf9EYv5gGSWtHX\%2F4YmgeOWvvqmS670\%3D\&tipoDoc=despacho\&cid=2061572.
} 
mayor y que la autoridad contratante debería soportar las consecuencias. Bien les hubiera venido a los contratistas entender que crisis económica y pandemia no son lo mismo (en todo caso, la segunda agravó la primera), y que las complicaciones de los contratos PPP viales ya existían. La pretensión de los contratistas se reducía a no cumplir a lo que se comprometieron, aunque habían asumido los riesgos. Además, todos los adjudicatarios podrían haber dado un paso al costado en junio 2018 pero prefirieron no hacerlo.

Decían en su demandas ${ }^{116}$ sin tapujos que Argentina había entrado hace varios años en una profunda crisis que restringió el acceso al financiamiento, y que fue generada por "acontecimientos políticos ocurridos en nuestro país y el excesivo endeudamiento externo que contrajo el gobierno nacional" ${ }^{117}$. De nuevo: todo eso ya se sabía al momento de la adjudicación. Y era más que evidente al año siguiente cuando se firmaron las Adendas.

Pero las partes actoras no se conformaron con eso, sino que también argumentaron que las obras y el cierre financiero habían sido suspendidas "sine die" por el comitente "ante la imposibilidad de conseguir créditos para financiar la ejecución del contrato" (lo que era, en rigor una obligación del contratista), "como lo prueban la suscripción de una Adenda por la cual se decidió el diferimiento del cierre financiero y del cronograma de obras principales" (que firmaron las dos partes, es decir que no fue una imposición). Y agregaban que lo expuesto quedaba corroborado por "el silencio guardado hasta hoy por la DNV con relación al futuro de estas obras".

El cinismo explicitado en las demandas es fabuloso, pero exhibe la calidad de contratistas de la Administración que tenemos.

116 Disponibles en http://scw.pjn.gov.ar/scw/viewer.seam?id=\%2B70lqb8E02\%2BNo00w1LFM3bqPNVop8Sfmpks3VTV1MYY\%3D\&tipoDoc=despacho\&cid=2851994 y http:// scw.pjn.gov.ar/scw/viewer.seam?id=IRq\%2FTUA6aGWiwG\%2BKJcI0y9Z\%2FjYSb3bRH2ciinOyiw5c\%3D\&tipoDoc=despacho\&cid=2052426.

117 Pero nada se decía sobre la deuda de los contratos PPP que era ocultada ilegalmente por ley, según se explicó más arriba. 
A su vez, ¿no sería un contrasentido suspender el contrato "sine die" hasta que el país se arregle? ¿Cuánta normalidad necesitan los contratistas en Argentina? ¿Es posible esa cantidad de normalidad?

Por lo pronto, parece que la cantidad de normalidad requerida para los contratos PPP supera a la que este país puede ofrecer.

Por su parte, la DNV en la apelación acusó que no existía ninguna medida que hubiere implicado la suspensión de obras o trabajos. Esto puede ser cierto en el plano formal, pero la DNV también debía reconocer los impedimentos que se enfrentaban. No existía un contrato en "plena ejecución", como señaló al expresar agravios ${ }^{118}$. Los contratos PPP viales ameritaban prontas soluciones tendientes a su terminación y honestidad de ambas partes.

\section{El informe de la Auditoría General de la Nación}

En fecha 29 de septiembre de 2020 la Auditoría General de la Nación (AGN) emitió la resolución 117/2020 que aprueba el "Informe de Auditoría, la Síntesis Ejecutiva y la Ficha del Informe que forma parte del mismo, realizado en el ámbito de la Subsecretaría de Participación Público Privada, la Dirección Nacional de Vialidad, el Ministerio de Transporte, el Ministerio de Economía y el BICE", que tuvo por objeto el "cumplimiento del régimen regulatorio de los contratos PPP-RARS"119. El periodo auditado fue el comprendido entre el 1/1/2017 y el 31/7/2018, etapa ya superada en este trabajo. Aunque se sugiere la lectura completa del informe, algunos de los hallazgos y las conclusiones de la AGN resultan tan contundentes que serán aludidos a continuación.

\footnotetext{
118 Documento disponible en http://scw.pjn.gov.ar/scw/viewer.seam?id=TB\%2Bwp6nK1M4 SgNFqGR8V\%2BIJ1pWyhDTDz9qz46dECrUc\%3D\&tipoDoc=despacho\&cid=2851424.

119 Resolución, informe, ficha y anexos disponibles en https://www.agn.gob.ar/informes/ cumplimiento-del-regimen-regulatorio-de-los-contratos-ppp-rars-corredores-b-c-e-f-y-sur.
} 
Además, con este informe la AGN dio cumplimiento al artículo 22 de la ley de contratos PPP, que establece que este organismo "deberá incluir en cada plan de acción anual la auditoría de la totalidad de los contratos de participación público-privada existentes, su desarrollo y resultado".

Primero, en palabras de la AGN, respecto a los contratos PPP viales no se encontraban "justificadas las razones por las cuales se considera que el interés público se verá mejor atendido mediante el régimen de PPP frente a otras alternativas contractuales" 120 .

Segundo, para la AGN "la mitigación prevista por dicha documentación para los riesgos financieros es insuficiente, dejando la ejecución de los contratos expuesta a variaciones desfavorables del contexto macroeconómico"121.

Tercero, la AGN juzga que "la decisión de llevar adelante el proyecto PPP bajo análisis no incluyó estimaciones razonables de costos, así como tampoco la certificación de ingresos suficientes para hacer frente a los pagos"122. Y no se analizó el descalce producido entre los activos del fideicomiso PPP y sus pasivos en dólares, ni la suficiencia de los primeros para afrontar los segundos. Esto tenía como consecuencia, al mismo tiempo, que no se previesen debidamente los posibles aportes contingentes presupuestarios. Incluso, según la AGN, las estimaciones presupuestarias eran inconsistentes con los compromisos asumidos ${ }^{123}$.

A su vez, la AGN recomienda "arbitrar los medios para registrar como deuda pública los pasivos contraídos por el Fideicomiso PPP, en la medida que su repago comprometa ingresos públicos futuros"124.

\footnotetext{
120 Informe AGN, p. 58.

121 Informe AGN, p. 48.

122 Informe AGN, p. 45.

123 Informe AGN, p. 56.

124 Informe AGN, p. 98.
} 
En resumen, el informe de la AGN coincide en el diagnóstico de los contratos PPP viales que se elaboró en este trabajo. Pero llegó un poco tarde.

\section{El fin de los contratos PPP viales}

Durante 2020 corrieron varios rumores sobre el final de los contratos PPP viales.

El 10 de enero de aquel año Ministro de Obras Públicas, Gabriel Katopodis, expresó en una entrevista radial que los contratos PPP viales fueron "una gran ficción", que allí solo había un "negocio financiero", y que se estaba realizando una auditoría. Asimismo, concluyó que el modelo había fracasado ${ }^{125}$.

En la misma línea, el Ministro Katopodis declaró en junio que el costo financiero de los contratos PPP viales hubiera sido enorme y que era inexplicable el financiamiento en dólares para obras que requieren insumos pagaderos en pesos ${ }^{126}$. Dijo también que las obras habían avanzado apenas un $2 \%$ y que el modelo debía ser desarmado porque era ruinoso y había causado perjuicios al Estado y los ciudadanos. En cuanto a la forma de extinción, señaló que estaba bajo análisis. Pero, claro, esto no era un tema menor.

En julio el Ministro envió una nota al titular de la DNV en la que le encomendó

"iniciar un proceso de evaluación de las distintas causales de extinción previstas contractualmente, referenciadas en la nota, y mantener reuniones de trabajo con los contratistas PPP, con el fin de poner término a los contratos PPP de conformidad con lo previsto en los mencionados contratos" ${ }^{\prime 27}$.

\footnotetext{
125 Radio 10, 10/1/2020, disponible https://ar.radiocut.fm/audiocut/entrevista-a-gabrielkatopodis-9342.

126 Radio La 990, 3/6/2020, disponible en https://www.youtube.com/watch?v=89E4frN8cfo.

127 Nota NO-2020-44992351-APN-MOP, 14/7/2020.
} 
Por su parte, la DNV solicitó a la Gerencia de Planeamiento y Concesiones y a la de Asuntos jurídicos que "inicien reuniones de trabajo con los contratistas PPP, a los fines de poner término a los contratos PPP en las condiciones más beneficiosas para el interés general, elaborando una propuesta de extinción de los contratos PPP y las condiciones aplicables a la misma" ${ }^{128}$.

Mientras tanto, dos contratistas presionaban por vía judicial y todo esto producía múltiples trascendidos periodísticos ${ }^{129}$.

El 24 de septiembre el Ministerio de Obras Públicas publicó un comunicado en su página de internet en el que informó que el cronograma de obras dispuesto en las Adendas no se había cumplido y que las empresas no habían podido realizar el cierre financiero ni habían incrementado el monto de la garantía por ese concepto. Además, se precisó que el 31 de agosto se había otorgado la posibilidad de "rescindir los contratos de común acuerdo hasta el 30 de noviembre" y que, "en este sentido, el Ministerio de Obras Públicas, a través de Vialidad Nacional, llegó a un acuerdo con la contratista PPP conformada por Helport SA, Panedile SA, Eleprint SA, COPASA (España), a cargo de los corredores E y F, para la extinción de los contratos"130.

Al día siguiente el Ministro Katopodis reapareció por radio y comentó que se encontraban en la recta final los cuatro contratos restantes, ya que si al 30 de noviembre no se hubieren rescindido de mutuo acuerdo, se les exigiría a contratistas el

\footnotetext{
128 Nota NO-2020-45296846-APN-DNV\#MOP, 15/7/2020.

129 8/6/2020: https://m.ambito.com/economia/obras/ppp-gobierno-desarma-mecanismomacri-obra-publica-n5108382; 19/7/2020: https://www.letrap.com.ar/nota/2020-7-19-9-33-0las-rutas-de-dietrich-katopodis-pone-primera-para-rescindir-los-ppp-viales; 17/8/2020: https:// www.baenegocios.com/economia/PPP-la-puja-por-las-garantias-traba-una-salida-consensuada-con-las-constructoras-20200817-0037.html; 2/9/2020: https://www.baenegocios.com/ economia/PPP-la-justicia-fallo-a-favor-de-Eurnekian-y-esperan-un-acuerdo-para-diciembre-20200902-0052.html;
}

130 Disponible en https://www.argentina.gob.ar/noticias/el-gobierno-nacional-rescindiolos-contratos-ppp-de-dos-corredores-viales. Las actas de extinción por estos corredores no fueron publicadas hasta varias semanas más tarde en un vínculo que ya no se encuentra disponible. 
cumplimiento del cierre financiero ${ }^{131}$, lo que conllevaría la extinción por su culpa.

Una parte de los corredores viales $\mathrm{E}$ y $\mathrm{F}$ fueron asignados -tras la extinción de los contratos PPP- para su administración a la DNV a través del decreto presidencial $779 / 2020^{132}$. Esa parte consta de 304 kilómetros. La novedad consistió en que por el mismo decreto se otorgó la concesión ("de obra pública por peaje", ley 17.520) de los 720 kilómetros restantes a Corredores Viales S.A.. Algo similar ya había ocurrido entre esa sociedad y la concesión de otros corredores viales, aquellos que iban a conformar la segunda etapa del plan vial PPP ${ }^{133}$. Pero Corredores Viales S.A. había sido creada por la gestión anterior y cuestionada por la actual. De ahí la sorpresa, si es que en la política puede usarse esa palabra.

Corredores Viales S.A. fue constituida por el decreto 794/2017. Está integrada por el Ministerio de Transporte (tenedor del $51 \%$ del capital social del Estado Nacional) y por la DNV (del 49\% restante). Su objeto original era bastante general y estaba relacionado con la construcción, conservación y explotación de redes viales nacionales. Algo parecido a lo que ya hacía la DNV. Tal fue el parecido que la entonces oposición acusó que se buscaba desplazar a aquel organismo. No obstante, pocos meses después se dictó el decreto 223/2018 que precisó que la sociedad estaría afectada a la gestión del Acceso Riccheri "y los corredores viales que el Estado Nacional le asigne". Por más de un año esos corredores viales a asignar fueron nulos y Corredores Viales S.A. abandonó el mar de dudas.

Por otro lado, el decreto 794/2017 había recibido un dictamen de rechazo por la Comisión Bicameral Permanente de

\footnotetext{
131 Radio 10, 25/9/2020, disponible en https://www.gustavosylvestre.com/anulan-contratos-ppp-fue-una-estafa-una-mentira-y-un-fracaso-rotundo-senalo-gabriel-katopodis.

132 Publicado en el Boletín Oficial en fecha 1/10/2020. Disponible en https://www.boletinoficial.gob.ar/detalleAviso/primera/235606/20201001.
}

133 Decreto 659/2019. 
Trámite Legislativo en noviembre de $2017^{134}$. La Comisión se pronunció por la invalidez de aquel decreto, que fue considerado un decreto delegado por haberse dictado en ejercicio de las potestades previstas por el artículo 5 de la ley $17.520^{135}$. Es decir que se basó en una delegación previa a 1994 que había caducado. Esto hacía que el decreto 794/2017 fuese -ademásinconstitucional.

De regreso a los contratos PPP viales, el 1 de diciembre de 2020 el Ministerio publicó otro comunicado en el que anunció la rescisión por mutuo acuerdo todos los contratos ${ }^{136}$.

Las actas de extinción se fundaron en el artículo $87^{137}$ de los contratos PPP viales y son muy similares ${ }^{138}$. Entre los motivos expresados en los antecedentes, se refiere a que a la fecha no se había logrado dar cumplimiento con la finalidad del Estado Nacional ni con las expectativas de cada contratista. Asimismo, se asentó que el Estado Nacional persigue la satisfacción del interés público, que se traduce en estos casos en "contar con una red de autopistas y rutas seguras", lo que justifica que se "deba hacer uso de marcos jurídicos alternativos a la ley

134 Versión taquigráfica de la reunión de fecha 21/11/2017 disponible en https://www. senado.gob.ar/upload/29106.pdf.

135 Artículo 5, ley 17.520: “El Poder Ejecutivo podrá crear sociedades anónimas mixtas con 0 sin mayoría estatal, de acuerdo a lo establecido por la ley 17.318, o entes públicos u otro tipo de persona jurídica para el cumplimiento de los fines previstos en la presente ley, haciendo el aporte de capital que considerare necesario o creando los fondos especiales pertinentes". Además, según el artículo 5 de la ley 25.152 (texto vigente al momento del dictado del decreto 794/2017) “toda creación de organismo descentralizado, empresa pública de cualquier naturaleza y Fondo Fiduciario integrado total o parcialmente con bienes y/o fondos del ESTADO NACIONAL requerirá del dictado de una Ley".

136 Disponible en https://www.argentina.gob.ar/noticias/obras-publicas/el-gobiernonacional-rescindio-de-comun-acuerdo-los-seis-contratos-ppp.

137 Artículo 87.2: “Como parte del acuerdo al que arriben las partes, el contratista PPP deberá reconocer y abonar al ente contratante los cargos de liquidación firmes; y el ente contratante deberá reconocer y abonar al contratista PPP el pago por inversión no amortizada. Las partes acordarán el monto, forma, condiciones y fecha de pago en el acta de extinción por mutuo acuerdo".

138 Disponibles en https://www.argentina.gob.ar/jefatura/ppp/contratos-registrados. 
$\mathrm{n}^{\circ} 27.328$ y dentro de esquemas económico financieros que resulten cumplibles".

Se acordaron los rubros que se incluirían en la extinción anticipada. A favor de los contratistas: pagos por inversiones no amortizadas, que comprenden montos reconocidos que aún no hubieren resultado en emisiones de TPI y otros montos reclamados por cada contratista a la DNV antes de la extinción de los $\operatorname{contratos}^{139}$. A favor del contratante: cargos de liquidación firmes (es decir gastos para reemplazar bienes afectados), montos de multas impuestas a contratistas y que estuvieren impagos, montos entregados con anticipación por explotación comercial y sumas reclamadas a contratistas en virtud de los contratos antes de su terminación ${ }^{140}$.

En cada acta se calculó el "saldo resultante de la propuesta de liquidación" "141 denominado en dólares y pagadero en pesos. Así, el total a abonar por el ente contratante a los contratistas con motivo de la extinción de los contratos PPP viales será de 14.635.439 dólares, sin contar los TPI y TPD emitidos. Demasiado por tan poco.

Además, los contratistas reconocieron no haber alcanzado el cierre financiero y se determinó que serían devueltas las garantías constituidas por ese rubro y por los demás (obras principales y servicios principales, cada una según diversos detalles y condiciones). También renunciaron a efectuar reclamos en cualquier foro o jurisdicción relacionados con sus correspondientes contratos, excepto lo concerniente al cumplimiento de cada acta de extinción, por supuesto, que "se resolverá mediante arbitraje".

\footnotetext{
139 Montos aproximados en dólares: corredor A, 7 millones; corredor B, 6 millones; corredor C, 5 millones; corredor E, 10 millones; corredor F, 6 millones; corredor Sur, 12 millones.

140 Montos aproximados en dólares: corredor A, 1 millón; corredor B, 5 millones; corredor $C$, 2 millones; corredor E, 9 millones de dólares; corredor F, 6 millones de dólares; corredor Sur, 4 millones.
}

141 Corredor A, 1.120.000 dólares; corredor B, 1.296.000 dólares; corredor C, 2.890.000; corredor E, 1.162.214 dólares; corredor F, 71.925 dólares; corredor Sur, 8.095.300 dólares. Total: 14.635 .439 dólares. 
En cuanto al personal de cada corredor vial, los contratistas asumieron responsabilidad por eventuales remuneraciones, indemnizaciones o deudas de empleados propios o que hubieren sido incorporados por ellos. A su vez, la DNV contrajo el compromiso de gestionar la incorporación del personal no comprendido anteriormente al nuevo operador.

El 22 de diciembre de 2020 se dictó el decreto de necesidad y urgencia $1036^{142}$ que concretó el fin de los contratos PPP viales. En los considerandos se repasan los antecedentes ya reseñados y se señala que la extinción de esos contratos dejó pendiente la ejecución de obras viales varias y que, por ello, se procede a utilizar instrumentos legales alternativos a la ley de contratos PPP para satisfacer las necesidades públicas.

Tal como ocurrió con el decreto 779/2020 y los corredores E y F, un segmento de los corredores A, B, C y Sur (de 337 kilómetros, correspondiente a rutas 7 y 3) se asignó a la DNV y otro a Corredores Viales S.A (de 1991 kilómetros). Así, 641 kilómetros de los ex contratos PPP viales quedaron bajo administración de la DNV y 2711 se otorgaron en "concesión de obra pública por peaje" ${ }^{143}$ a Corredores Viales S.A..

Asimismo, ante "el avance mínimo de las obras, muy por debajo de aquellos compromisos asumidos por los ex contratistas PPP", se dispuso con urgencia la afectación de fondos que recibían los contratos PPP viales para obras y mantenimiento de los corredores que serán gestionados por la DNV y Corredores Viales S.A. En consecuencia, se desarticuló el esquema previo de Fideicomiso PPP, que recibía recursos del SISVIAL y que supuestamente tiene resto para afrontar las obligaciones de pago pendientes derivadas de los contratos PPP viales extinguidos. Si la solución siempre estuvo allí (fondos públicos y/o

\footnotetext{
142 Publicado en el Boletín oficial en fecha 22/12/2020, disponible en https://www.boletinoficial.gob.ar/detalleAviso/primera/239047/20201223.

143 Y por diez años, según el artículo 3 inciso b del decreto 1036/2020. Lo mismo dispone el artículo 3 inciso b del decreto 779/2020.
} 
concesión por peaje), habría que preguntarse otra vez para qué se necesitaban los contratos PPP.

\section{Epílogo}

Los contratistas en Argentina no son todos iguales. Ni deben serlo, sin perjuicio de la igualdad de trato en los procedimientos contractuales ${ }^{144}$. A su vez, es razonable implementar un "trato más favorable" a algunos contratistas para determinados proyectos $^{145}$. Incluso la Constitución Nacional abre la puerta para eso en su "cláusula del progreso" 146 . En todo caso, deberíamos preguntarnos para qué contratistas y para qué proyectos. Progreso sí, pero no de cualquier manera ni a cualquier costo.

Tal vez haya llegado la hora de ser prudentes en los presupuestos, las programaciones de contrataciones y la elaboración y aplicación de normas. Si se tomase o privilegiase un solo aspecto, es probable que las soluciones no sirvan. $\mathrm{Y}$ en cada supuesto no hay que olvidar quiénes estarán del otro lado. No es lo mismo la provisión de insumos médicos estandarizados que la construcción de un hospital. Si se proveerá un trato especial, no debe ser para cualquiera ni para cualquier cosa.

A esta altura del siglo XXI damos por sentadas cosas que antes eran inimaginables. A todo el Estado -no solo a la Administración- le pedimos que funcione de manera eficiente para satisfacer un catálogo amplio de derechos ya considerados

\footnotetext{
144 Consagrada en el artículo 3, inciso f, del decreto 1023/2001 y en el artículo 12 de la ley 27.328

145 En ese sentido, ver: MIRAL, Héctor A. - VERAMENDI, Enrique V., op. cit.

146 Artículo 75, inciso 18: "Proveer lo conducente a la prosperidad del país, al adelanto y bienestar de todas las provincias, y al progreso de la ilustración, dictando planes de instrucción general y universitaria, y promoviendo la industria, la inmigración, la construcción de ferrocarriles y canales navegables, la colonización de tierras de propiedad nacional, la introducción y establecimiento de nuevas industrias, la importación de capitales extranjeros y la exploración de los ríos interiores, por leyes protectoras de estos fines y por concesiones temporales de privilegios y recompensas de estímulo".
} 
fundamentales $\mathrm{y}$, por lo tanto, universales e indisponibles ${ }^{147}$. Para lograrlo, a veces debe contratar con personas privadas. Hasta los contratos PPP, la principal -o única- vía consistía en lo que se denomina contratos administrativos. Más allá de cada modalidad y sus detalles, los contratos por los que el Estado busca garantizar derechos fundamentales no deben estar sometidos prioritariamente a necesidades o leyes del mercado.

Sobre las contrataciones administrativas en general ya me he referido al comienzo de este trabajo. Por las dudas, reitero que no pienso que hayan sido bien ideadas o ejecutadas. También sostengo que sus problemas están más ligados a la ejecución que al diseño normativo. Y en la ejecución están involucrados la Administración y los contratistas. En particular, los que no proveen resmas o tubos de ensayo, sino los que construyen. Por eso, darle más estos últimos y hacerlo bajo sus reglas y según lo que imponga el mercado financiero no parece la mejor forma de concretar un paso adelante en contrataciones del Estado y, en particular, de la Administración.

Podemos pensar que los contratos PPP viales fracasaron porque no se consiguió el financiamiento. Así, si se quisiera continuar con PPP, tan solo habría pensar en cómo conseguir financiamiento privado en términos razonables. Además, ya se sabe que en este país contratistas no faltan, lo que faltan son financistas.

Sin embargo, en la película de los contratos PPP pasó mucho más que lo que aparece en la foto del final de los contratos PPP viales. Aquí se hizo un repaso de lo que fue esta primera etapa legal. Se la anunció casi como una solución mágica. Pero la varita estaba rota.

La programación de proyectos PPP fue temeraria, sin dudas. $\mathrm{E}$ intuyo que hay consenso en que se debe concretar y realizar todo lo que estaba previsto en los presupuestos 2018 y 2019

147 FERRAJOLI, Luigi (2019). Manifiesto por la igualdad. Editorial Trotta, Madrid, p. 15 y ss. 
por modalidad PPP y más. Argentina necesita obras e infraestructura para robustecer derechos. No obstante, en mi opinión, es evidente que todo eso (todo lo que programó) no debía concretarse con contratos PPP. Primero, nunca quedó claro por qué todo eso se haría con contratos PPP. Mucho menos, por qué haría con PPP todo lo que podía hacerse por concesión de obra pública. Pero, claro, el anterior Gobierno quería hacer de todo con PPP. Creyó en eso. Le salió mal y Argentina perdió, como mínimo, mucho tiempo y dinero.

Por otro lado, según se expuso, hay objetos contractuales que por su calidad y cantidad no deben cursarse por la ley 27.328. Solo la complejidad técnica, las limitaciones presupuestarias y el largo plazo podrían imponer la modalidad PPP. A lo que habría que agregar que, en lo posible, los proyectos que versen sobre la satisfacción directa de derechos fundamentales no queden atados a prioridades privadas. Se debe aceptar que los contratistas hagan su negocio, por supuesto. De hecho, nada indica que hasta ahora con contratos administrativos tradicionales hayan perdido. Pero no se debe conceder que lo hagan trasladando un costo financiero alto (el que se compone, además, de mayores precios finales y de más requerimientos del sector privado) y limitaciones para el Estado y para el interés público. Otra vez: el funcionamiento pasado y actual del Estado no invita a pensar que es, en estas condiciones, el agente perfecto para promover mejores condiciones de vida y derechos, pero es el que tenemos. Y ojalá un día funcione tan bien que se pueda acercar a ese ideal de eficiencia y eficacia.

Si se intentasen de nuevo los contratos PPP, ese intento deberá ocurrir en un contexto de equilibrio financiero del Estado. Con el perfil de deuda que tiene Argentina, parecería que los contratos PPP han entrado en estado hibernación. Ahora bien, coincido con Carlos Balbín ${ }^{148}$ respecto a que el fracaso

\footnotetext{
148 Ver su exposición en el marco de la jornada "Mito y realidad de los contratos de participación público privada", 29/6/2020, Facultad de Derecho, UBA, disponible en https://www.
} 
no se dio por solo por el contexto económico-financiero, sino también por su estructura jurídica ${ }^{149}$. Los contratos PPP viales demostraron que la difuminación de las presuntas asimetrías entre las partes terminaron por beneficiar a los contratistas, quienes, bajo el amparo de la "flexibilidad", impusieron su voluntad en las modificaciones de pliegos, en los contratos y las Adendas. Así, en palabras de Balbín, las reglas nucleares no fueron claras, predeterminadas ni fuertes, sino que fueron establecidas y redefinidas, ya sea directa o indirectamente, por los contratistas. Esos contratos PPP viales quedaron exentos de normas de Derecho administrativo y hasta de orden público $\mathrm{y}$ fueron sometidos al financiamiento privado. El final no fue acorde a los presagios de 2016. O quizás sí, si se tomasen como referencia las experiencias en otros países.

Asimismo, de cara a una nueva edición de contratos PPP, será oportuno que se cumplan varias disposiciones de la ley que no fueron debidamente implementadas en los casos viales, por ejemplo, aplicar mecanismos de supervisión (artículo 4 inciso a), ponderar la rentabilidad social de los proyectos (4.e), incentivar la responsabilidad fiscal (6), determinar un equitativo reparto de riesgos (6.b), justificar la modalidad respecto a otras formas contractuales (13.a), evaluar los costos y beneficios (13.h), garantizar la participación y transparencia (14) y excluir a quienes revistan incompatibilidades o no cumplan con las pautas sobre anticorrupción (23 y 24).

Por último, sería conveniente que, en cualquier escenario, el Estado celebre contratos provechosos para la ciudadanía, no para abogados y financistas.

youtube.com/watch?v=DjttczMGrOU. También en http://www.derecho.uba.ar/derechoaldia/ notas/mito-y-realidad-de-los-contratos-de-participacion-publico-privada-ppp/+8063.

149 A lo que, por mi parte, agrego: y por una deficiente estrategia política y presupuestaria. 